\title{
Öz’ün Söz Üzerine Etkileri: Kendilik Tutarlılığı, Beden İmajı ve İletişim Becerileri Arasındaki İlişkilerin İletişim Öğrencileri Özelinde İncelenmesi
}

\author{
Murat SEZGIN* Şakir GÜLER**
}

- Geliş Tarihi: 28.08.2020 • Kabul Tarihi: 25.11.2020 • Çevrimiçi Yayın Tarihi: 25.11.2020

\section{$\ddot{\mathbf{O z}}$}

$\mathrm{Bu}$ araştırmanın amacı "beden imajı algısının" ve "kendilik tutarlılığının" iletişsim becerileri üzerindeki etkisini keşfetmektir. Çalışma genel tarama modeli tarzında desenlenmiş olup veriler kesitsel olarak toplanmıştır. Araştırma yordayıcı türdedir. Bu doğrultuda Süleyman Demirel Üniversitesi iletişim fakültesi öğrencileri, araştırmanın çalışma evrenini oluşturmaktadır. Evren içerisinde yer alan öğrencilerin okul numaraları referans alınarak basit rastgele örnekleme yöntemiyle 308 katılımcı örneklem olarak belirlenmiştir. Araştırma sonunda ulaşılan bulgulara göre; katılımcıların beden imajı algıSı \%24.2 oranında, kendilik tutarlılıkları ise \%2.3 oranında iletişim becerilerini etkilemektedir. Öte yandan beden imajı ve kendilik tutarlılı̆̆ 1 arasında pozitif yönde anlamlı ilişki saptanmıştır. İletişim becerileri açısından kadınların erkeklere göre daha yetkin olduğu saptanmıştır. Çalışma iletişim becerilerini kapsamlı bir şekilde ele alarak kendilik tutarlılığ 1 ve beden imajı açısından incelemektedir. Bu yönüyle literatüre yeni bir bakışs sunmaktadır. Sonuçlar, yalnızca dış çevreden alınan söylemlerin beden imajı üzerindeki etkili olmadığını aynı zamanda beden imajının da iletişim becerileri üzerinde etkili olduğunu göstermektedir. Araştırma beden imajının iletişim becerileri üzerindeki etkisini ele alması sebebiyle gelişmekte olan literatüre katkı sağlamaktadır.

Anahtar sözcükler: beden imajı, kendilik tutarlılığı, iletişim becerileri, benlik saygısı, iletişim eğitimi

\section{Atıf:}

Sezgin, M. ve Güler, Ş. (2021). Öz’ün söz üzerine etkileri: kendilik tutarlılığı, beden imajı ve iletişim becerileri arasındaki ilişkilerin iletişim öğrencileri özelinde incelenmesi. Pamukkale Üniversitesi Eğitim Fakültesi Dergisi, 52, 206-234.doi:10.9779.pauefd.787237

\footnotetext{
* Doç. Dr., Uşak Üniversitesi, İletişim Fakültesi, Halkla İlişkiler ve Reklamcılık Bölümü, Orcid: 0000-0003-2200-3301, murat.sezgin@usak.edu.tr

** Araş. Gör. Süleyman Demirel Üniversitesi, İletişim Fakültesi, Halkla İlişkiler ve Tanıtım Bölümü, Orcid: 0000-00027365-6639, sakirguler@yandex.com.
} 


\section{Giriş}

21. yüzyıl iletişim olgusunun hızla dönüştüğü ve giderek karmaşıklaştığı bir süreç olarak ön plana çıkmıştır. Gelişen teknoloji ve aktarılan kültürel miras ${ }^{1}$, bir yandan nicelik olarak iletişim kurma sürecini kolaylaştırırken diğer taraftan bilgi iletişim teknolojilerinin neden olduğu bazı olumsuz gelişmeler², sağlıklı iletişim kurma sürecini tehdit etmektedir (Zivnuska, Carlson, Carlson, Harris ve Harris, 2019). Bu sebeple içinde yaşadığımız yüzyıl, iletişim olgusunun teknik olarak etraflıca bilinmesi ve bu konudaki becerilerin geliştirilmesi gereken bir dönemdir (Ersanlı ve Balc1, 1998). Iş1k’a (2017) göre iletişim duygu, düşünce ve eylem imgelerinin kaynaktan alıcıya sözlü ve sözsüz biçimlerde çeşitli kanallar aracılığıyla aktarıldığı bir süreçtir. Bireyler doğduğu ilk anlardan itibaren dış çevreyle iletişime geçme amacı güderler (Ersanlı \& Balcı, 1998). Dahası henüz çocukluk döneminde dahi etkileşime geçilen ya da maruz kalınan unsurlar, kişinin ilerleyen dönemdeki iletişim becerileri üzerinde etkili olmaktadır (Liberman, Woodward, Keysar ve Kinzler, 2017). Gerek sosyal dünyanın inşası ve sürdürülebilirliği açısından gerek yaşam kalitesinin iyileştirilebilmesi adına iletişim becerileri kişisel yaşamda önemli rol oynamaktadır (Wiemann, 2003; Stewart, Zediker ve Witteborn, 2005). Dolayısıyla günümüzde iletişim becerilerinin ilişki arz ettiği bağlamları ele alan araştırmalar önem taşımaktadır. Beden imajı algısı ve kendilik algısı da iletişim becerileriyle ilişki arz eden oldukça önemli bağlamlardır.

Yapılan araştırmalarda; olumsuz beden imajına sahip bireylerin sosyal ortamlardan kaçındığı, iletişim kurmada daha çekingen davrandıkları görülmektedir (Foustanos, Pantazi ve Zavrides, 2007; Vani, Pila, Wilson ve Sabiston, 2020). Aynı zamanda sahip olunan benliğin/kendiliğin diş çevreye sunumunda da iletişim becerileri önemli bir etkendir. Bireyler benliklerine yönelik bilgileri dış çevreye sunarken muhataplarının izlenimini olumlu yönde etkilemek adına çeşitli iletişim becerilerine sahip olmalıdırlar (Goffman, 2014; Ünal, 2011). Dahası iletişim becerileri ve kendilik kavramının karşılıklı bir etkileşime

\footnotetext{
${ }^{1}$ İletişim kurma amaciyla "sesli ve yazılı" sembollerde kaydedilen gelişmeler, kültürel bir miras olarak gelecek kuşaklara aktarılmaktadır. Böylece günümüze dek konuşma ve yazı dillerinde birçok ilerleme kaydedilmiştir. Benzer bir biçimde bu kültürel birikimler, düşünsel kavramların gelişimine de aracılık ettiğinden iletişim süreçleri olumlu yönde etkilenmektedir.

${ }^{2}$ Bilgi iletişim teknolojilerinin gelişimiyle birlikte insanlar; cep telefonu, sosyal medya ve diğer iletişim aygıtlarını kullanarak, zaman ve mekân bağlılığı olmadan eskiye nazaran daha hızlı iletişim kurma firsatı yakalamıştır. Öte yandan bu teknolojiler kaynağı belli olmayan çarpıtılmış (dezenformatif) mesajların yayılımına da aracılık ettiğinden sağlıklı iletişim sürecini tehdit etmektedir. Ayrıca bu iletişim aygıtlarının kullanımı (ör. sosyal medya) bireylerin iradeleri dışında çeşitli uygulamalara bağımlılık kazanmasına neden olmaktadır. Dolayısıyla bireyler bir yandan bu yenilikler sayesinde zaman ve mekân sınırlaması olmaksızın iletişim kurma firsatı yakalıyorken diğer yandan yüz yüze iletişim kurma becerilerinde aksaklıklar meydana gelebilmektedir (Allred \& Atkin, 2020).
} 
sahip olduğu düşünülmektedir. Nitekim araştırmalar, çeşitli eğitimlerle iletişim becerilerini geliştiren bireylerin benlik algılarının da olumlu yönde değiştiğini ortaya koymaktadır (Ünal, 2011).

Bu nedenle "kendilik kavramı" ve "beden imajına" dair algıların iletişim becerileri ile olan ilişkisini kavrayabilmek adına ilgili kavramlara daha yakından bakmak gerekmektedir.

Kendilik kavramı genel itibariyle bireyin kendisiyle ilgili algıları olarak tanımlanmaktadır (Marsh ve Shavelson, 1985). Diğer bir yaklaşımla kendilik; öz olarak bireyselliğe atfedilen duygu ve düşüncelerin bütünü olarak da ele alınmaktadır (Rosenberg, 1989). Bu bağlamda bireyin dış çevre ile kurmuş olduğu temaslar, söz konusu algıların oluşmasında elzemdir (Shavelson, Hubner ve Stanton, 1976). Diş çevre ile etkileşimde bulunan birey bu durumun bir sonucu olarak, içsel açıdan da herhangi bir duygu ya da eylem üzerinde kendiliğine yönelik çeşitli betimlemelerde bulunmaktadır. Marsh ve Shavelson (1985) bu noktada "ben bu işte iyiyim", “oldukça mutlu bir insanım” gibi söz konusu betimlemelerin de kendiliği şekillendirdiğini ifade etmektedir.

Sherif ve Cantril kendilik kavramını ego olarak isimlendirirken, Allport proprium olarak (akt. Korkmaz, 1996), Erikson (1956) ego kimliği olarak, kavramın öncüsü William James (1983) ise bilen benlik "I" ve bilinen benlik "me" olarak ele almaktadır. Oyserman, Elmore ve Smith (2012), alandaki araştırmacıların, kendilik kavramını hem bir durum olarak hem de durum ve eylemleri şekillendirmenin bir sonucu olarak anlamlandırdığını ifade etmektedir. Dolayısıyla literatürde yer alan kendilik kavramı ile ilgili açıklamaların geniş bir alana uzandığ 1 ifade edilebilir.

Literatürde yer alan kendilik tanımlarına hitaben Hattie (2014) ise kavramı çeşitli boyutlarda tanımlamaktansa, onun etkileşimde bulunduğu diğer faktörleri ortaya koyarak kendiliği anlamlandırmak gerektiğinden bahsetmektedir. Bu noktada; fizikçilerin elektrik kavramını ele alış biçimini örnek gösteren Hattie (2014), bir fizikçiye göre elektriği tanımlamanın saçma olduğunu, elektriğin ancak işlevsel yönlerini keşfederek ve ilgili olduğu bağlamları ortaya koyarak bireyler için anlamlı hale getirilebileceğini belirtmektedir. Elektriği tanımlamaya çalışmaktan ziyade, kavramın nasıl kullanılması gerektiği, diğer değişkenlere nasıl tepkiler verdiği ve kavramın özelliklerini bilmenin neden değerli olduğu gibi konular kendilik kavramı için de geçerlidir. Bu araştırma kapsamında ise (motivasyonel bağlamda) kendilik kavramının (Elliott, 1986) iki temel bileşeninden biri olan kendilik tutarlılığının (KT) iletişim becerileri üzerindeki etkisi araştırılacaktır. 
"Kendilik tutarlılığını- KT" (self-consistency) tanımlamaya geçmeden önce, bireylerin nesneler dünyasını keşfetmesiyle birlikte dış dünyanın gerçekliğini "öteki” bilinciyle deneyimlediklerini belirtmek gerekmektedir. Kendilik temsillerinin yeni yeni oluşması nedeniyle bireyin dünyaya geldiği bebeklik döneminde ve çocukluk yıllarında kendilik kavramı henüz tutarlı bir biçime sahip değildir. Öte yandan kendilik imgelerinin zamanla bir biçeme bürünmesi ve kişinin bu doğrultuda davranışlar sergilemesi kendilik sürekliliği ya da kendilik tutarlılı̆̆ tutarlılı̆̆ izlemesi, bütünlük arz etmesidir. Bu nedenle kendilikle uyuşmayan bir deneyim, tutarlılık arz etmediğinden kolay özümsenememekte, kişi böylesi durumlarda zor bir onarım süreci içerisine girmektedir (Elliott, 1986).

Kendilik tutarlılığı, benlik kavramının korunması ve sürdürülmesi için gerekli olan iki temel motivasyon (güdü) kaynağından birisidir. Bireyin benlik görüntüsünü değişikliklere karşı koruyup, kendiliğin sürdürülmesine yardımcı olmaktadır. Bir diğer benlik güdüsü ise benlik saygısı (BS) kavramıdır. Benlik saygısı bireyin kendisine güven duyması, değer vermesi ve saygı addetmesi gibi konularda motivasyon sağlamaktadır (Elliott, 1986; Korkmaz, 1996). Benlik kavramının korunması ve sürdürülmesi için gerekli iki temel bileşen olan BS ve KT oldukça güçlü pozitif bir ilişkiye sahiptir. Fakat mevcut araştırmanın deseni gereği çalışma kapsamında kendilik tutarlılığı üzerinden araştırma hipotezleri inşa edilecektir.

BS ve KT arasındaki pozitif yöndeki güçlü ilişside BS, KT’yi etkilemektedir (Elliott, 1986). Düşük benlik saygısına sahip kişilerin, sahip oldukları kimlikten mutsuz oldukları, kendilerini eksik ve değersiz hissettikleri alan yazında yer alan araştırmalarda birçok kez ortaya koyulmuştur (Donnellan, Trzesniewski, Robins, Moffitt ve Caspi, 2005; Righetti, Visserman, 2018). Dolayısıyla benlik saygısı düşük bireyler sahip oldukları kendilik imajından hoşnut olmadıklarından değişime sıcak bakmaktadır. Bu nedenle söz konusu kişilerin kendilik kavramları daha az tutarlı olma eğilimindedir (Elliott, 1986). Bu noktada bireylerin sahip oldukları kendiliklerinin farkına vararak mevcut durumlarını olumlu yönde geliştirmeleri gerekmektedir (Ünal, 2011).

Nitekim sahip olunan kendilik algısını olumlu yönde değiştirebilmek için bireyin yalnızca benliğine yönelik kişisel algılarını değiştirmesi yeterli değildir. Kendilik farkındalığı ve benlik saygısı gibi benliğe dair temel bileşenler, hem diş çevreden (Shavelson, Hubner ve Stanton, 1976; Sezgin ve Güler, 2020) hem de kişinin sahip olduğu 
iç dinamiklerden (ör. genetik faktörler, algılar vb.) etkilenmektedir (Neiss, Sedikides ve Stevenson, 2002; Giananti, 2020). Dolayısıyla kendilik algısı üzerinde dış çevrenin sahip olduğu izlenimler önemlidir. Bu hususta Goffman (2014) bireyin dâhil olduğu sosyal ortamlarda benliğine dair sunmuş olduğu izlenimleri "iletişim kanalıyla” yönetebileceğini ifade etmektedir. Dolayısıyla bireyin bu izlenimleri iletişim aracılığıyla yönetebilmesi için çeşitli iletişim becerilerini kullanması, öğrenmesi gerekmektedir (Ünal, 2011). Goffman (2014) özellikle sözlü simgeler aracılığıyla benliğe dair izlenimleri yayma ve yönetme faaliyetlerine "verilen izlenim" başlığı altında değinmektedir. Bireyin konuşarak ya da diğer sözlü simgeler aracılığıyla dış çevrenin kendisi hakkındaki tutumlarını tayin edebileceğini, varsaymaktadir.

Bu kapsamda kendilik tutarlılığı ve benlik saygısı düşük bireylerin sahip olduğu kendiliği olumlu yönde değiştirebilmeleri ve benlik saygılarını artırabilmeleri için iletişim becerilerinden de faydalanabilecekleri düşünülmektedir. Nitekim Vatankhah, Daryabari, Ghadami ve Naderifar'ın (2013) ortaokul öğrencileri üzerinde yapmış olduğu araştırmaya göre, 8 hafta boyunca, haftada 90 dakikalık iletişim becerileri eğitimi alan öğrencilerin, kontrol grubundaki diğer öğrencilere nazaran ciddi ölçüde benlik saygılarının arttığ1 sonucuna ulaşılmıştır. Ünal (2011) tarafından üniversite öğrencileri üzerinde yapılan bir diğer araştırmaya göre bireyler; kendilerine yöneltilen eleştirileri dinleme, fikirlerini ifade edebilme ve gerektiği durumlarda muhataplarından talepte bulunma veya kendilerine yöneltilen talepleri reddedebilme gibi iletişim becerilerini geliştirdiklerinde bireylerin kendilik algılarının da olumlu yönde değiştiği sonucuna ulaşmıştır (Ünal, 2011). Benzer bir şekilde bireylerin sahip olduğu iletişim becerilerinin artmasıyla kendilerine olan güvenlerinin ve iyimser tutumlarının arttığı görülmüştür (Razı vd., 2009).

Bu nedenle araştırmanın ilk hipotezi (H1), benlik saygısı ve kendilik tutarlılığ düşük bireylerin değişebilmek için iletişim becerilerini ${ }^{3}$ de geliştirmeleri gerekeceği varsayılarak oluşturulmuştur.

Benlik saygısı yüksek bireyler ise aksine sahip oldukları kendilikten memnuniyet duymaktadırlar. Zaaflarının farkında olan bu kişiler, onları iyileştirme ihtiyacı hissetmeden bir yaşam sürmekte, sahip oldukları kendiliği değiştirme amacı gütmezler (Elliott, 1986). Bu

\footnotetext{
$3 \mathrm{Bu}$ araştırma kapsamında iletişim becerileri; bireyin duygu ve düşüncelerini açıkça ifade edebilmesini, kendine dair özellikleri özgürce dışa vurabilmesini, kendine güvenebilmesini, muhatapları üzerindeki iletişim hakimiyetini ve sosyal açıdan rahatlığını ifade etmektedir (Bienvenu, 1971; Rubin \& Martin, 1994). Illetişim kavramı ise, bireyin aktarmak istediği mesajı çeşitli kanallar aracılığıyla alıcıya iletmesi' anlamında kullanılmaktadır. Dolayısıyla iletişim becerilerindeki temel amaç bireyin alıcıya ulaştırmak istediği mesajı hedefe başarılı bir şekilde iletebilmesini konu almaktadır.
} 
kapsamda benlik saygısı yüksek bireylerin 'kendiliklerinin tutarlı oluşundan' hoşnut olmaları beklenmektedir (Engel, 1959). Bu doğrultuda benlik saygısı ile kendilik tutarlılığı arasında pozitif yönlü ilişki beklenmektedir. Literatürde yer alan çalışmalar incelendiğinde benlik saygısının yüksek oluşunda dış görünüşün ve beden imajının rolü oldukça büyüktür (Befort ve Christie, 2001; Lowery vd., 2005; Hwang, 2017). Dolayısıyla araştırmanın ikinci hipotezi $\mathrm{H} 2$ bu kavramsal temele dayanarak oluşturulmuştur.

Beden imaj1 kavramı ilk olarak The Image and Appearance of the Human Body adlı monografide, "bedenimizin zihnimizde oluşan fotoğrafı" olarak tanımlanmıştır (Schilder'dan akt. Slade, 1994). İlerleyen dönemlerde ise tanım; zihnimizdeki fotoğrafa yönelik duygularımızı ve algılarımızı da kapsayacak şekilde genişlemiştir (Grogan, 2006; Slade, 1994). 1996 yılına dek gerçekleştirilen araştırmaların, beden imajına yönelik duyguları ve tutumları içeren iki bileşeni birbirinden ayırt etme noktasında yetersiz kaldığı ileri sürülmüştür (Gardner ve Rick, 1996). İlerleyen dönemlerde ise beden imgesine dair bileşenlerin daha fazla olduğu belirtilmiş olup; algı, tutum, biliş, davranış, cazibe, şişmanlık korkusu, vücut bozukluğu, vücut memnuniyetsizliği ve diyet gibi konular bu kapsamda değerlendirilmiştir (Banfield ve McCabe, 2002). Söz konusu boyutlar geniş bir yelpazeye uzanmasına rağmen 2006 yılına dek beden imgesini konu alan çalışmaların daha çok bedenle ilgili memnuniyetsizlikler ve zayıf olma isteği üzerinde durduğu görülmektedir (Grogan, 2006).

Demografik değişkenler açısından beden imajını ele alan araştırmalarda ise; yaş, ırk ve cinsiyet temalı araştırmaların ön plana çıktığı görülmektedir. Cinsiyet bağlamında literatürdeki genel kanaat, kadınların kendilerini gerçekte olduğundan daha olumsuz bir görüntüye sahip olarak algıladığı, erkeklerin ise kadınlara nazaran mevcut görüntülerinden daha memnun olduğu yönündedir (Ata, Ludden ve Lally, 2007; Demarest ve Allen, 2000; Morken, Røysamb, Nilsen ve Karevold, 2019). Bu doğrultuda kadın ve erkeklerin beden imajı algılarının farklılık gösterdiği varsayılabilir (H3-H4).

Etnisite (1rk) açısından ise daha çok Amerika merkezli araştırmalar gerçekleştirilmiştir. Bu çalışmalarda Afro-Amerikan bireylerin bedenlerine dair tutumlarının diğer gruplara nazaran daha olumlu ve tutarlı olduğu bildirilmektedir (Demarest ve Allen, 2000; Miller, Gleaves, Hirsch, Green, Snow ve Corbett, 2000; Schooler, Ward, Merriwether ve Caruthers, 2004).

Yaş açısından beden imajını ele alan çalışmalarda ise ilk dikkat çeken unsur, örneklem olarak kadınların daha sık tercih edilmesidir (Cusumano ve Thompson, 2001). 
Yaşlanma ile birlikte vücut memnuniyetsizliklerinin 50'li yaşlara dek giderek arttı̆g fakat 50'li yaşlardan sonra azaldığı belirtilmektedir (Becker, Diedrichs, Jankowski ve Werchan, 2013). Beden imajı kapsamında 9-18 yaş aralığı gibi daha erken yaş grupları üzerinde gerçekleştirilen çalışmalarda ise; "geleneksel ve yeni medyanın" beden imajı üzerindeki etkileri daha sık sorgulanmıştır. Bu kapsamda Clark ve Tiggemann'ın (2007) ilkokula giden k1z çocukları üzerinde (n265) gerçekleştirdiği araştırmanın sonuçlarına göre; akran sohbetleri, TV şovları ve magazin dergileri vücut memnuniyetsizliğinin oluşmasında önemli rol oynamaktadır. Negatif medya mesajlarına maruz kalma durumu özellikle daha alt yaş gruplarındaki (6-9 yaş) bireylerin beden imajı algısına ciddi zararlar vermektedir (Slater ve Tiggemann, 2016). Bu yüzden yaşa bağlı olarak beden imajı algısında değişim beklenebilir (H5).

Öte yandan beden imajını konu alan araştırmalar incelendiğinde; beden imajı algısının ve iletişim becerilerinin birlikte ele alındığı bir araştırma modeline rastlanmamaktadır. Fakat iletişim becerileri kapsamında değerlendirilebilecek bazı alt faktörlerin, beden imajı açısından incelendiği çeşitli çalışmalara rastlamak mümkündür. Kavramlar arasındaki etkileşimi daha yakından görmek adına bu çalışmalara değinmek gerekmektedir.

Ceyhan, Ceyhan ve Kuryılmaz'ın (2012) 492 Türk öğrenci üzerinde gerçekleştirdiği araştırmaya göre beden imajı algısı, problem çözme becerileri üzerinde anlamlı etkiye sahiptir. Bu doğrultuda beden imajından memnun olan bireylerin daha iyi problem çözme becerisine sahip oldukları ifade edilmektedir. Öte yandan beden imajından memnun olmayan öğrencilerin ise daha fazla depresyon belirtisi yaşayabileceği vurgulanmaktadır. Woodrow-Keys'in (2006) üniversiteli kadınlar üzerinde yaptığı araştırmada ise düzenli spor yapan bireylerin daha olumlu beden imajı algısına sahip olduğu, bu bireylerin beden imajı algılarının girişken olmalarında etkili bir faktör olduğu belirtilmektedir. Bireylerin sosyal çevrede fikirlerini özgürce ifade etmesi ve iletişim sürecini yönetmesi açısından girişkenlik önemli bir iletişim becerisi olarak değerlendirilmektedir (Bienvenu, 1971; Rubin ve Martin, 1994). Rumsey ve Harcourt'un (2004) kaleme aldığı derlemede ise olumsuz beden imajına sahip ve görünüş açısından çeşitli dezavantajları olan (vücudun uzuvlarında doğuştan ya da sonradan meydana gelen bozulmalar, hastalıklar vs.) bireylerin sosyal etkileşim kurma konusunda sorun yaşadığı, yeni insanlarla tanışmaktan çekindiği ve uzun vadeli ilişkiler geliştirmekte zorlandıkları görülmektedir. Bu doğrultuda bazı bireyler, daha olumlu bir beden imajı algısına sahip olabilmek için cerrahi operasyon dahi geçirebilmektedir. Bu 
durumu konu alan Foustanos, Pantazi ve Zavrides (2007) tarafindan gerçekleştirilen bir araştırmada ise; estetik ameliyat sonrasında bireylerin eskiye nazaran daha olumlu beden imajı algısına sahip olduğu ve kendilerine olan güvenlerinin arttığı sonucuna ulaşmışlardır. Araştırmacılar aynı çalışma kapsamında diğer değişkenler sabit tutulduğunda, algılanan beden imajının kişilerarası ilişkileri olumlu yönde etkilediğini, olumlu beden imajına sahip bireylerin doğal olarak kendilerine güvenlerinin de arttığını belirmektedirler. Kendine güvenme durumu da iletişim becerileri kapsamında değerlendirilmektedir (Bienvenu, 1971; Rubin ve Martin, 1994). Fakat Foustanos, Pantazi ve Zavrides'in (2007) yaptığı bu araştırmada algılanan beden imajının yanında dış çevreden alınan pozitif geri bildirimlerin de kişilerarası ilişkileri olumlu yönde etkilediği ifade edilmektedir.

Dolayısıyla literatürde beden imajının iletişim becerileri üzerindeki etkisini araştıran araştırmalar oldukça sınırlıdır. Ayrıca bu araştırmalar iletişı̇ becerilerini kapsamlı bir biçimde ele almak yerine belirli iletişim becerileri üzerine odaklanmaktadır. $\mathrm{Bu}$ nedenle beden imajının iletişim becerileri üzerindeki etkisini doğrudan sorgulayan bir modele rastlanmamıştır.

Beden imajı ve "iletişim” ögesini birlikte ele alan araştırmaların daha çok "dış çevreden alınan geri bildirimlerin beden imajı üzerindeki etkisine odaklandığı görülmektedir (Kichler ve Crowther, 2009; Pole, Crowther ve Schell, 2004).

Örneğin Kichler ve Crowther (2009), erken ergenlikteki kız öğrenciler üzerinde gerçekleştirdikleri araştırmada, dış çevreden alınan geri bildirimler bir iletişim ögesi olarak değerlendirilmiş olup, bu geri bildirimlerin kız öğrencilerin beden imajları üzerindeki etkisi incelenmiştir. Dolayısıyla kız öğrencilerin vücutlarından memnun olmama durumları ile çevreden aldıkları negatif söylemler arasında anlamlı ilişki tespit edilmiştir. Katılımcıların vücutlarından memnun olmamaları hususunda akranlardan alınan olumsuz geri bildirimlerin, aileden alınan geribildirimlerden daha etkili olduğu belirtilmiştir.

Yine bir diğer araştırmada da evli kadınların vücut memnuniyetsizlikleri üzerinde; eşlerinden almış oldukları geri bildirimlerin etkili olduğu görülmüştür (Pole, Crowther ve Schell, 2004). Söz konusu araştırmalarda da görüldüğü üzere, literatürde vücut imajı ile "iletişim” kavramının ilişkilendirildiği modellerde, iletişim kavramı daha çok "çevreden alınan geri dönütler" şeklinde kodlanmaktadır. Beden imajı algısının iletişim becerileri üzerindeki etkisini inceleyen sınırlı literatür ise beden imajının iletişim becerileri üzerinde etkili olduğunu göstermektedir. 
$\mathrm{Bu}$ araştırma kapsamında ise algılanan beden imajının (BİA) kişisel iletişim becerileri (IB) üzerindeki etkisi araştırılmaktadır (H6). Çalışma iletişı̇ becerilerini kapsamlı bir biçimde ele almaktadır. $\mathrm{Bu}$ yönüyle alan yazına katkı sağlayacağı varsayılmaktadır.

Dolayısıyla uygulama bölümüne geçmeden önce benden imajı algısıyla ve kendilik kavramıyla ilişkili olduğu düşünülen “iletişim becerileri” kavramına kısaca değinmek gerekmektedir.

İletişim becerileri kısaca, etkili dinleme ve etkili tepki verme olarak özetlenmektedir (Korkut, 1996). İletişim becerileri, kazanılan tecrübelerle şekillenmektedir. İletişim becerilerinin amacı kurulan iletişimin sağlıklı şekilde gerçekleşmesini sağlamaktır. Literatürde iletişim becerilerinin öğrenilme sürecinde cinsiyet merkezli farklılıklar olduğu vurgulanmaktadır. Kadınların duygu ve düşüncelerini daha açık ifade ettiği, erkeklere nazaran daha sosyal ve duyarlı tavırlar sergiledikleri aktarılmaktadır (Korkut, 1996). Dolayısıyla kadınların iletişim becerilerinin erkeklere kıyasla daha iyi olduğu ileri sürülebilir (H7).

$\mathrm{Bu}$ araştırmada iletişim becerileri, kapsam olarak Bienvenu'nun (1971) ve Rubin ve Martin'in (1994) geliştirdiği Kişilerarası İletişim Envanterleri referans alınarak tayin edilmiştir. Dolayısıyla çalışmanın referans aldığı iletişim becerileri içerik olarak on bir temel unsuru içermektedir. Bunlardan ilki insanların başkalarıyla iletişim kurmasına olanak sağlayan sağlıklı/yeterli bir benlik kavramıdır. Bu sıralamayı iyi bir dinleyici olma özelliği, duygu ve düşünceleri açıkça ifade edebilme özverisi (kendini ifade etme), kendini başkalarına doğru ve özgürce ifade etme isteği (dışa vurum), çevresel hakimiyet, cana yakınlık, etkileşim yönetimi, muhatap odaklılık, kendine güven, sosyal rahatlık ve empati gibi başlıklar takip etmektedir (Bienvenu, 1971; Rubin ve Martin, 1994). Fakat araştırmada kullanılan iletişim becerileri ölçeği tek bir faktör olarak değerlendirildiğinden bu on bir beceri, iletişim becerisi başlı̆̆ olarak kavramsallaştırılmıştır.

Araştırmanın amacı iletişim becerileri üzerinde beden imajı algısının ve kendilik tutarlılığının rolünü sorgulamaktır. Nitekim iletişim fakültesi öğrencilerinden gerek mesleki yaşamlarında gerek sosyal hayatlarında etkili bir iletişimci olmaları beklenmektedir. Bu çerçevede araştırmanın uygulama bölümünde, iletişim fakültesi öğrencilerinin iletişim becerileri üzerinde kendilik tutarlılıklarının ve beden imajı algılarının rolü irdelenecektir. Çalışmanın hipotezleri aşağıdaki gibidir; 
- H1: Kendilik tutarlılığı (KT) iletişim becerilerini ${ }^{4}$ etkilemektedir.

- H2: Katılımcıların beden imajı algıları ile (BİA) kendilik tutarlılıkları (KT) arasında pozitif yönde anlamlı bir ilişki vardır.

- H3: Katılımcıların beden imajı algıları (BİA) cinsiyetlerine göre farklılaşmaktadır.

- H4: Kadınların beden imajı algıları (BİA) erkek katılımcılardan daha düşük ortalamaya sahiptir.

- H5: Katılımcıların beden imajı algıları (BİA) yaşlarına göre farklılaşmaktadır.

- H6: Katılımcıların beden imajı algıları (BİA) iletişim becerileri (İB) üzerinde anlamlı etkiye sahiptir.

- H7: İletişim becerileri (İB) cinsiyete göre farklılaşmaktadır.

\section{Yöntem}

Araştırma, nicel (survey) yöntem dâhilinde değişkenler arası ilişkisel tarama modeli üzerine kurgulanmıştır. Tarama modellerinde, evrende yer alan çok sayıdaki birim içinden seçilen örneklem üzerinde araştırma gerçekleştirilerek ulaşılan çalışma sonucu ile evrenin geneline yönelik bilgi edinme amacı güdülmektedir (Karasar, 1984; Punch, 2013; Neuman, 2014). Veriler niceleyici araştırma metotlarından anket (survey) tekniği ile toplanmıştır. Araştırmanın çalışma grubu, veri toplama araçları ve verilerin analiz edildiği istatistiki testlere yönelik detaylar bu bölümde aktarılmaktadır.

\section{Katılımcılar}

Çalışmanın soyut evrenini iletişim fakültesi öğrencileri oluşturmaktadır. Öte yandan ulaşılabilir dairedeki hedef/çalışma evreni (Karasar, 1984) ise Süleyman Demirel Üniversitesi (SDÜ) İletişim Fakültesi öğrencilerinden oluşmaktadır. 2019-2020 eğitimöğretim dönemi itibariyle SDÜ İletişim Fakültesinde; Halkla İlişkiler ve Tanıtım, Gazetecilik, Radyo-Televizyon ve Sinema, olmak üzere toplamda 3 aktif bölüm ve kayıtlı 1232 öğrenci bulunmaktadır. Öğrencilerin okul numaraları referans alınarak temellendirilen

\footnotetext{
${ }^{4} \mathrm{Bu}$ araştırma kapsamında iletişim becerileri; bireyin duygu ve düşüncelerini açıcça ifade edebilmesini, kendine dair özellikleri özgürce dışa vurabilmesini, kendine güvenebilmesini, muhatapları üzerindeki iletişim hâkimiyetini ve sosyal açıdan rahatlığını ifade etmektedir (Bienvenu, 1971; Rubin \& Martin, 1994). İletişim kavramı ise, bireyin aktarmak istediği mesajı çeşitli kanallar aracılığıyla alıcıya iletmesi' anlamında kullanılmaktadır. Dolayısıyla iletişim becerilerindeki temel amaç bireyin alıcıya ulaştırmak istediği mesajı hedefe başarılı bir şekilde iletebilmesini konu almaktadır. Bu nedenle kavramlar anlam açısından güçlü bir etkileşime sahiptir.
} 
çalışma evreni içerisinden basit rastgele örnekleme (simple random sample) yöntemiyle 328 öğrenci örneklem olarak (gönüllülük esaslı) seçilmiştir. Basit rastgele örnekleme yönteminde çalışma evreninin sınırları net olarak bilinmek durumundadır. Öte yandan evren içerisindeki her birimin örnekleme seçilme şansı eşittir (Böke, 2014). Verilerin analizi sırasında özensiz doldurulduğu tespit edilen 20 anket formu çalışma dışı bırakılarak gerekli analizler 308 kişilik örneklem kümesi üzerinden gerçekleştirilmiştir.

\section{Veri Toplama Araçları}

Veriler nicel araştırma metotlarından anket (survey) tekniği ile toplanmıştır. İlgili araştırma anketi; Kişilerarası İletişim Yetkinliği Formu (KIYYÖ), Kendilik Tutarlılığı Ölçeği (KTÖ), Bedeni Beğenme Ölçeği (BBÖ) ve Kişisel Bilgi Formu (KBF) dâhilinde yer alan soru maddelerinden oluşmaktadır.

\section{Kişilerarası İletişim Yetkinliği Ölçeği (KIYŸ)}

Kişilerarası İletişim Yetkinliği Ölçeği (Interpersonal Communication Competence Scale ICCS), Rubin ve Martin (1994) tarafından 477 öğrenci üzerinde likert tarzı bir ölçek olarak geliştirilmiştir. KIYYÖ’nün geliştirildiği ilk halinde 60 maddelik soru mevcuttur. Bu forma ait güvenilirlik değeri $\alpha=.77$ olarak hesaplanmıştır. Ölçeğin 30 maddelik formuna ait güvenilirlik değeri ise $\alpha=.87^{\prime}$ dir. Alt boyutlara ait güvenilirlik değerlerinin $\alpha=.41$ ile $\alpha=.72$ arasında değişmekte olduğu saptanmıştır. $\mathrm{Bu}$ nedenle yazarlar ölçeğin alt boyutlara ayrılmadan tek bir boyut halinde kullanımını tavsiye etmektedirler. Ölçeğin geçerliliği ise uyum geçerliliği yöntemiyle test edilerek $(\mathrm{r}=.52, \mathrm{p}<.01)$ katsayı alfa güvenilirliğinin $\alpha=.71$ olduğu sonucuna ulaşılmıştır (Rubin ve Martin, 1994). Bu araştırma kapsamında ise ölçeğe ait güvenilirlik katsayısı $\alpha=.82$ olarak hesaplanmıştır. Ölçeğin yapı geçerliliğini teyit etmek amacıyla açıklayıcı faktör analizi (AFA) ve doğrulayıcı faktör analizi (DFA) gerçekleştirilmiştir. AFA esnasında KIYYÖ’e ait bütünle uyuşmayan 5 madde atılmıştır. DFA değerleri ise ölçeğin mevcut yapısının ideal uyuma sahip olduğunu göstermiştir $\left(\chi^{2} / \mathrm{sd}\right.$ $=4.244, \mathrm{GFI}=.92, \mathrm{CFI}=.90, \mathrm{TLI}=.90, \mathrm{NFI}=.90, \mathrm{IFI}=.90, \mathrm{RMSEA}=.01$ ve $\mathrm{SRMR}=.01$ ).

Kendilik Tutarlılı̆̆ı Ölçeği (KTÖ)

KTÖ Rosenberg (1965) tarafından geliştirilen benlik saygısı ölçeğinin (RBSÖ) bir alt boyutudur. Benlik saygısı ölçeği toplamda 63 maddeden oluşmaktadır ve 12 alt boyuta sahiptir. RBSÖ'nün geneline yönelik test-tekrar test katsayısı $\mathrm{r}=.82-.88$ arasında değişmekteyken, güvenilirlik düzeyi ise $\alpha=.77-.88$ arasında değişmektedir. Ölçeğin 
geçerlilik ve güvenilirlik çalışmaları Çuhadaroğlu (1986) gerçekleştirilerek test-tekrar test katsayısı $\mathrm{r}=.48-.79$ olarak tespit edilmiştir. Schmitt ve Allik (2005) tarafından gerçekleştirilen bir araştırmada RBSÖ’nün evrensel kültüre uygunluğu sınanarak ölçeğin evrensel bir ölçek olma özelliği taşıdığı bildirilmiştir.

$\mathrm{Bu}$ araştırma kapsamında "kendilik tutarlılığg”" olarak isimlendirilen "kendilik kavramının sürekliliği” alt boyutuna dair güvenilirlik değeri $\alpha=.75$ olarak hesaplanmıştır. Ölçeğin geçerliliği faktör analizi ile teyit edilmiştir. Faktör analizi sırasında bütünle uyuşmadığı tespit edilen 1 madde ölçekten atılmıştır. Ölçeğin açıkladığı toplam varyans $\% 58,473$ olarak hesaplanmıştır.

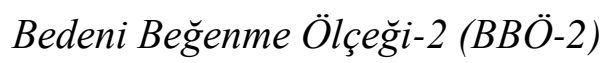

Bedeni Beğenme Ölçeği-2, Tylka ve Wood-Barcalow (2015, s. 58) tarafından 13 maddelik BBÖ (Orijinal Adı: Body Appreciation Scale -BAS) ölçeğinin yeniden düzenlenmesi nihayetinde 820 kadın ve 767 erkek katılımeı üzerinde likert tarzı bir ölçek olarak geliştirilmiştir. Maddeler olumlu yönde kodlanmıştır. 10 maddelik BBÖ-2 ölçeğinin güvenilirlik katsayısı kadın ve erkek katılımcılar için $\alpha=.94$ ve $\alpha=.93$ olarak saptanırken testtekrar test güvenilirliğine dair korelasyon katsayısı $\mathrm{r}=.90$ olarak tespit edilmiştir. Ölçeğin geçerlilik ve güvenilirlik çalışmaları ise Anlı, Akın, Eker ve Özçelik (2015) tarafından iç tutarlılık analizi ve DFA yöntemleriyle gerçekleştirilmiştir. Bu neticede ölçeğe ait güvenilirlik değeri $\alpha=.88$ olarak, DFA değerleri ise $\mathrm{x}^{2}=72.46, \mathrm{sd}=33, \mathrm{RMSEA}=.077$, $\mathrm{CFI}=.98, \mathrm{IFI}=.98, \mathrm{RFI}=.95, \mathrm{GFI}=.93, \mathrm{SRMR}=.045$ olarak hesaplanmıştır.

$\mathrm{Bu}$ araştırma kapsamında BBÖ-2 aracına yönelik güvenilirlik değeri $\alpha=.89$ olarak hesaplanmıştır. BBÖ-2'nin bu araştırma kapsamında açıkladı̆̆ı toplam varyans \% 54,090 'dir.

\section{Kişisel Bilgi Formu (KBF)}

KBF'de katılımcıların yaş, cinsiyet, kardeş sayısı, yaşamlarının çoğunu geçirdikleri yer ve ekonomik gelirleri gibi sosyo-demografik bilgilere yönelik sorular yer almaktadır.

\section{Araştırmanın Modellenmesi}

Araştırmanın amacı doğrultusunda hipotezlerin yönünü ve türünü betimleyen araştırma modeli Şekil 1'de gösterildiği gibidir. 


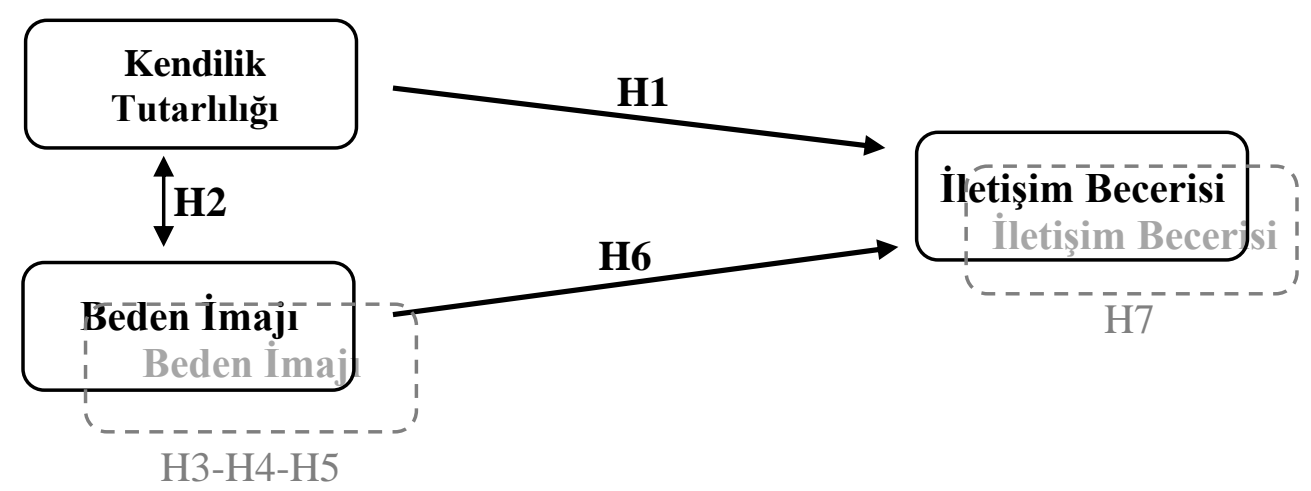

Şekil 1. Araştırma Modeli

\section{İşlem}

Araştırma verileri 2019-2020 eğitim-öğretim bahar döneminde toplanmıştır. Katılımcılar araştırma hakkında bilgilendirilerek araştırmaya katılım gönüllülük esasına dayandırılmıştır. Araştırma ile ilgili etik onay, Süleyman Demirel Üniversitesi Etik Kurulu'ndan 25.06.2020 tarihinde 92/3 sayılı karar ile alınmış olup, mevcut prosedür etik kararlar çerçevesinde yürütülmüsştür. Öte yandan demografik sorular başta olmak üzere katılımcılara, yanıtlamak istemedikleri soruları boş bırakabilecekleri ifade edilmiştir. Her bir katılımcı için uygulama yaklaşık 6-14 dakika sürmüştür.

\section{Verilerin Analizi}

Tablo 1'de gösterildiği üzere araştırma değişkenlerinin ( $\mathrm{n}>30)$ basıklık değerleri -0.28 ile +0.19 arasında, çarpıklık değerleri ise -0.66 ile +0.12 arasında değişmektedir. Hair, Black, Babin, Anderson ve Tatham'a (2014) göre basıklık ve çarpıklık değerlerinin \pm 1.0 olması verilerin normal dağıldığını göstermektedir. Dolayısıyla araştırma hipotezleri SPSS 24.0 paket programı aracılığıyla parametrik testler ile sınanmıştır. İlişki hipotezleri Pearson Korelasyon katsayısı hesaplanarak analiz edilirken, etki hipotezleri ise basit doğrusal Regresyon analizleri ile teste tabi tutulmuştur. Değişkenler arası farklılaşmayı konu alan hipotezler ise ANOVA ve Independent Samples T Testleri ile sınanmıştır. Öte yandan katılımcıların demografik durumlarına yönelik veriler Frekans Analizi ile betimlenmiştir. 
Tablo 1. Araştırma Değiş̧kenlerine Yönelik Ortalama, Standart Sapma, Basıklık ve Çarpıklık Dĕ̌gerleri

\begin{tabular}{lcccccccc}
\hline & & & & & \multicolumn{2}{c}{ Çarpıklık } & \multicolumn{2}{c}{ Basıklık } \\
\cline { 6 - 10 } & Min. & Max. & $\overline{\mathrm{x}}$ & SS & \multicolumn{1}{c}{ Istatistik Std. H. İstatistik Std. H } \\
\hline İletişim Becerileri & 2.72 & 5.00 & 3.8697 & .42731 & .039 & .139 & -.210 & .277 \\
Kendilik Tutarlılığı & 1.00 & 5.00 & 2.9852 & .91506 & .125 & .139 & -.285 & .277 \\
Beden İmajı Algısı & 2.22 & 5.00 & 4.1166 & .66350 & -.666 & .139 & .194 & .277 \\
\hline
\end{tabular}

\section{Bulgular}

Katılımcıların yaş, cinsiyet, kardeş sayısı, yaşamlarının çoğunu geçirdikleri yer ve ekonomik gelirleri gibi sosyo-demografik durumlarına yönelik bulgular Tablo 2'de aktarılmaktadır. Tablo 2. Katılımcıların Sosyo-Demografik Özelliklerine Yönelik Bulgular

\begin{tabular}{llcc} 
& Sıklık & Yüzde \\
\hline Yaş & $18-20$ & 81 & 26,3 \\
& $21-23$ & 153 & 49,7 \\
& $27-26$ & 56 & 18,2 \\
& 30 ve üzeri & 6 & 1,9 \\
& Toplam & 12 & 3,9 \\
& Kadın & 308 & 100,0 \\
& Erkek & 156 & 50,6 \\
& Toplam & 152 & 49,4 \\
& Kardeşim Yok & 308 & 100,0 \\
& 2 kardeşiz & 21 & 6,8 \\
& 3 kardeşiz & 131 & 42,5 \\
& 4 kardeşiz & 80 & 26,0 \\
Kardeş Sayısı & 5-7 kardeşiz & 34 & 11,0 \\
& 8 ve üzeri & 32 & 10,4 \\
& Toplam & 10 & 3,2 \\
& İl Merkeziydi & 308 & 100,0 \\
\hline & & 185 & 60,1 \\
& & &
\end{tabular}


İlçeydi

Hayatlarının ÇoğunuKasabaydı

Geçirdikleri Yer

Ekonomik Gelir
92

29,9 
artması, iletişim becerilerini de olumlu bir biçimde etkilemektedir. Kendilik tutarlılığının ise iletişim becerileri üzerinde \%2,3 gibi oldukça düşük bir etkisi söz konusudur. Katılımcıların KT düzeylerindeki bir birimlik artış iletişim becerileri üzerinde 0.7 birimlik artışa sebep olmaktadır. H1 hipotezinin test edilmesinde ek olarak ANOVA testinden de yararlanılmıştır. Nitekim “H1: Kendilik tutarlılığı (KT) iletişim becerilerini etkilemektedir" önermesinde araştırmanın amacı doğrultusunda; KT düzeyi düşük bireylerin ideal benliklerine ulaşma amacıyla farklı söylem ve davranışlara yöneleceği varsayımı göz önünde bulundurulmaktadır. Bunun temel nedeni şudur; benlik saygısı düşük bireyler mevcut kendiliğinden memnun olmadığından sahip oldukları kendiliği değiştirmek istemektedirler. $\mathrm{Bu}$ doğrultuda söz konusu kişiler değişime sıcak baktığından tutarlı bir benliğe de sahip olmaları beklenemez. Bireyin kendisiyle ilgili olumsuz yönlerini değiştirme çabaları ve sahip olmaya çalıştığı yeni özellikleri içselleştirmesi ise çeşitli iletişim becerine sahip olmayı gerektirmektedir. Daha önceki paragraflarda bahsedildiği üzere kişinin kendine yönelik algılarının oluşmasında iç dinamikler ve dış çevreden alınan geri bildirimler önemlidir. Bu nedenle kendilik tutarlılığı düşük bireylerin dış çevreye verdiği izlenimleri yönetmesi ve çeşitli iletişim becerilerini geliştirmesi gerekmektedir. KT düzeyi düşük katılımcılar arasında mevcut kendilik algısını iyileştirmek isteyenlerin; sosyal rahatlık, etkileşim yönetimi, dışa vurum, dinleme becerisi, empati ve daha birçok iletişim becerisinde olumlu yönde değişim beklenebilir. Bu beceriler kişiden kişiye değişebilir. Dolayısıyla regresyon analizi sonuçlarına ek olarak KT düzeyi düşük bireylerin iletişim becerilerine de değinmek yerinde olacaktır. Bu analizi yapmaktaki temel amaç, KT düzeyi düşük, orta ve yüksek bireylerin iletişim becerilerinin ne düzeyde olduğunu görünür kılmaktır.

KT veri setine ait ortalamalar düşük, orta ve yüksek olmak üzere üç ayrı kategori tayin edilerek kategorik değişken haline getirilmiştir. Gerçekleştirilen Anova testi nihayetinde KT düzeylerine göre katılımcıların iletişim becerileri anlamlı şekilde farklılaşmıştır $(p>.05)$. İkili gruplar arasındaki anlamlı farklar incelendiğinde (Tukey) kendilik tutarlılığı yüksek bireylerin iletişim becerileri, orta düzey iletişim becerisine sahip katılımcılara $\left(.15169^{*}\right)$ göre daha yüksektir. Öte yandan iletişim becerilerine yönelik ortalamalar incelendiğinde KT düzeyi düşük katılımcıların $\overline{\mathrm{x}}=3.9$, KT düzeyi orta olan katılımcıların $\overline{\mathrm{x}}=3.8, \mathrm{KT}$ düzeyi yüksek katılımcıların ise $\bar{x}=4.0$ oranında iletişim becerisi düzeyine sahip olduğu görülmektedir. Dolayısıyla kendilik tutarlılığı düşük katılımcıların iletişim becerilerinin, KT düzeyi orta olanlardan yüksek olması, H1 hipotezini kısmen desteklemektedir. Muhtemelen KT düzeyi daha düşük bireyler olumlu yönde değişim gösterebilmek amaciyla iletişim 
becerilerini geliştirmek için daha yoğun çaba göstermektedirler. Bir diğer ifadeyle KT düzeyi düşük seyreden bireylerin iletişim becerilerini geliştirmek amacıyla farklı söylem ve davranışlar geliştirerek ideal kendilik kavramlarını arayış içinde oldukları yorumu yap1labilir. $\mathrm{Bu}$ doğrultuda Tablo 3'te yer alan R2 katsayısından ve ilgili Anova testi bulgularından hareketle $\mathrm{H} 6$ ve $\mathrm{H} 1$ hipotezi kısmen kabul edilmiştir. İlgili bağlamın netleştirilmesi ve alanyazının zenginleştirilmesi adına daha fazla araştırma yapılması gerekmektedir.

Katılımcıların beden imajı algıları ile kendilik tutarlılıkları arasındaki ilişkiyi konu alan H2 hipotezinin test edildiği korelasyon analizine yönelik değerler Tablo 4'te sunulmaktadır. Aynı zamanda katılımcıların beden imajı algıları ve iletişim becerileri arasındaki ilişki de Tablo 4'te gösterilmektedir.

Tablo 4. Değişkenler Arası Korelasyon Analizi

\begin{tabular}{lccc}
\hline & BíA & KT & İB \\
\hline Beden İmajı Algısı (BİA) & 1 & $.217^{* *}$ & $.490^{* *}$ \\
Kendilik Tutarlılı̆̆ (KT) & $.217^{* *}$ & 1 & $.150^{* *}$ \\
İletişim Becerileri (İB) & $.490^{* *}$ & $.150^{* *}$ & 1 \\
\hline
\end{tabular}

$* * \mathrm{p}<.01, * \mathrm{p}<.05$

Pearson korelasyon analizi sonucunda öğrencilerin beden imaj algıları ile kendilik tutarlılıkları arasında $(\mathrm{r}=.217, \mathrm{p}<.01)$ pozitif yönde anlamlı ilişki saptanmıştır. Öğrencilerin bedenlerine yönelik olumlu tutumlarının artmasıyla kendilik tutarlılıklarının da pozitif yönde artacağı yorumunda bulunulabilir. Bu kapsamda H2 hipotezi kabul edilmiştir. Diğer yandan Tablo 4'te aktarıldı̆̆ı üzere katılımcıların beden imajı algıları ile iletişim becerileri arasında pozitif yönlü bir ilişki $(r=.490, p<.01)$ söz konusudur. Söz konusu ilişkinin yorumlanmasında toplanan verilerin türü ve konunun içeriği etkilidir. Literatürde r'nin 0.8 'den büyük olduğu durumlarda ilişki oldukça güçlü olarak, r'nin 0.5 'ten küçük olduğu durumlarda ilişki zayıf olarak nitelendirilebilmektedir. Öte yandan ilişkinin gücünü yorumlamada bu değerler göreceli bir yapıya sahip olup konunun içerik ve verinin türüne göre yorumlama değişebilmektedir (Samuel ve Ethelbert, 2015). Dolayısıyla Tablo 3'teki regresyon sonuçları da göz önünde bulundurulduğunda; katılımcıların beden imajı 
algılarının olumlu bir dairede seyretmesi, iletişim becerilerini pozitif olarak geliştirebilir. Daha net çıkarımda bulunabilmek için bu konuda yeni araştırmalar yapılması gerekmektedir. Tablo 5. Cinsiyete Göre Beden Imajı Algisı: T-Testi

\begin{tabular}{lccccccc}
\hline & Cinsiyet & $\mathbf{N}$ & $\overline{\mathbf{x}}$ & SS & S. Hata & T & P \\
\hline Beden İmaj1 Alg1s1 (BİA) & Kadın & 156 & 4.1639 &, 65897 &, 05276 & & \\
& Erkek & 152 & 4.0680 &, 66680 &, 05408 & &
\end{tabular}

Katılımcıların beden imajı algılarının cinsiyete göre farklılaşacağı' önermesinde bulunan H3 hipotezi, gerçekleştirilen t testi sonucunda $(p>.05)$ reddedilmiştir. Kadın katılımcıların BİA ortalamalarının erkeklere kıyasla daha düşük düzeyde olacağını konu edinen H4 hipotezi de Tablo 5'te yer alan "kadın: $\bar{x}=4.1$; erkek: $\bar{x}=4.0$ " bulgusuna dayanılarak reddedilmiştir.

Beden imajı algısının yaşa göre farklılaşmasını konu edinen H5 hipotezine yönelik ANOVA testi sonucunda katılımcıların beden imajı algılarının yaşa göre istatistiki yönden anlamlı olarak $(\mathrm{p}>$.05) farklılaşmadığı sonucuna ulaşılmıştır. Bu doğrultuda H5 hipotezi de reddedilmiştir. Nitekim katılımcılar üniversite öğrencisi olduğu için çoğunun yaşı birbirine yakın aralıktadır. Literatürde yaşlanmaya bağlı olarak beden imajı açısından bir değişim beklenmektedir (Becker, Diedrichs, Jankowski ve Werchan, 2013). İlgili ANOVA test sonuçları Tablo 6'da sunulmaktadır.

Tablo 6. Beden Imajı Algısının Yaşa Göre Farklılaşma Durumu

\begin{tabular}{lccccc}
\hline $\begin{array}{l}\text { Varyansın } \\
\text { Kaynă̆ı }\end{array}$ & $\begin{array}{c}\text { Kareler } \\
\text { Toplamı }\end{array}$ & ss & Kareler Ort. & F & p \\
\hline Gruplar arası & 3,320 & 4 &, 830 & 1,908 &, 109 \\
\hline Gruplar içi & 131,833 & 303 &, 435 & \\
\hline Toplam & 135,153 & 307 & & \\
\hline $\mathrm{p}>.05$ & & & & &
\end{tabular}


İletişim becerilerinin kadın ve erkek katılımcılar özelinde farklılaşacağı önermesinde bulunan H6 hipotezine yönelik T-Testi sonuçları Tablo 7'de gösterilmektedir.

Tablo 7. Cinsiyete Göre Illetişim Becerileri: T-Testi

\begin{tabular}{lccccccc}
\hline & Cinsiyet & N & $\overline{\mathbf{x}}$ & SS & S. Hata & T & P \\
\hline İletişim Becerileri (İB) & Kadin & 156 & 3,9244 &, 41309 &, 03307 & & \\
& Erkek & 152 & 3,8137 &, 43569 &, 03534 & & \\
& & & & & & &
\end{tabular}

Tablo 7'ye göre kadın katılımcılar erkeklere nazaran iletişim konusunda kısmen daha yüksek ortalamaya sahiptir. Dolayısıyla istatistiki olarak $(p<.01)$ kız öğrencilerin iletişim hususunda erkeklerden daha yetkin olduğu ifade edilebilir. İlgili bağlamın netleştirilmesi ve daha tutarlı çıkarımda bulunabilmek adına yeni araştırmaların yapılması gerekmektedir. Tablo 7'de yer alan verilerden hareketle bu çalışma için $\mathrm{H} 7$ hipotezi istatistiki sonuçlara dayanarak kabul edilmiştir. Aradaki farkın düşük bir değere sahip olduğunu da belirtmek gerekir.

Özet olarak H1-H2-H6-H7 hipotezleri kabul edilirken H3-H4-H5 hipotezleri reddedilmiştir.

\section{Tartışma ve Sonuç}

'Beden imajı' ve 'kendilik tutarlılığının' iletişim becerileri üzerindeki etkisinin sorgulandığı bu araştırmada; iletişim eylemini meslek olarak icra edecek iletişim fakültesi öğrencileri üzerine bir araştırma gerçekleştirilmiştir. Ulaşılan bulgulara göre; algılanan beden imajı, iletişim becerilerini anlamlı bir biçimde etkilemektedir. Kavramsal arka planda da bahsedildiği üzere literatürde iletişim olgusu daha çok çevreden alınan geri dönütler biçiminde beden imajı algısı ile ilişkilendirilmektedir (Kichler ve Crowther, 2009; Pole, Crowther ve Schell, 2004; Arroyo ve Andersen, 2016).

Öte yandan beden imajının iletişim becerileri üzerindeki etkisini ele alan sınırlı sayıdaki geçmiş araştırma ise (Ceyhan, Ceyhan ve Kuryılmaz, 2012; Woodrow-Keys, 2006; Rumsey ve Harcourt, 2004; Foustanos, Pantazi ve Zavrides, 2007) beden imaj1 algısının iletişim becerileri üzerinde anlamlı etkisi olduğunu göstermektedir. Dolayısıyla H6 hipotezine ait bulgular mevcut literatürü desteklemektedir. Fakat geçmiş araştırmalar iletişim becerilerini daha alt bileşenler üzerinden ele almaktadır (ör. kendine güven, girişkenlik, sosyal etkileşim vb.). Bu araştırma kapsamında ise iletişim becerilerini konu 
alan veri toplama aracı belirli bir iletişim becerisi ile sınırlı değildir. İletişim becerilerini kapsayan on bir temel unsura yer verilmektedir . Dolayısıyla çalışmanın konu edindiği iletişim becerileri daha kapsamlıdır. Araştırma sonunda ulaşılan bulgulara göre beden imajı algısı, kişinin iletişim becerileri üzerinde pozitif yönde etkilidir. Dolayısıyla beden imajı algısının iletişim becerilerini hem etkilediği hem de genel anlamda iletişim süreçlerinden etkilendiği yorumunda bulunulabilir.

Araştırmanın çıktılarına göre kendilik tutarlılı̆̆ 1 ise iletişim becerileri üzerinde istatistiki açıdan oldukça düşük bir etkiye sahiptir (H1). Bu nedenle kavramlar arasında bir ilişki olduğu ifade edilebilir. Fakat değişkenler arası etkinin tanımlanabilmesi için farklı örneklem kümeleri üzerinde yeni araştırmalar gerçekleştirilmesine ihtiyaç duyulmaktadır. Örneklemin seçildiği üniversite öğrencilerinin psikolojik çerçevede henüz kişilik özelliklerinin oluşmaya devam ettiğini belirtmek gerekmektedir. Nitekim katılımcıların \%76'sı 18 ile 23 arasında bir yaşa sahiptir. Literatürde kendilik kavramı üzerine gerçekleştirilen araştırmalar incelendiğinde; daha üst yaş gruplarındaki bireylerin kendilik tutarlılıkları ile iletişim ögesini merkeze alan sosyal ifade biçimleri (ör: yerel yönetime katılım) arasında anlamlı ilişki tespit edilmiştir (Güler ve Sezgin, 2020). Öte yandan kendilik tutarlılığı düşük katılımcıların ideal benliklerine ulaşma gayretiyle farklı söylem ve davranış biçimleri geliştireceğini konu edinen $\mathrm{H} 1$ hipotezi istatistiki açıdan kabul edilmiştir. $\mathrm{Bu}$ durumun alanyazın için önem arz ettiği düşünülmektedir. Bilhassa KT'si yüksek ve düşük kategorisinde yer alan bireylerin iletişim becerilerinin, KT’si orta düzeydeki katılımcılardan daha yüksek olması, gelecek araştırmalar için dikkat çekicidir. KT düzeyi düşük bireyler iyi yönde değişebilmek amacıyla, iletişim becerilerine daha çok önem veriyor olabilir.

Katılımcıların beden imajı alg1ları ile kendilik tutarlılıkları arasında (H2) tespit edilen pozitif yöndeki anlamlı ilişki $(r=.217, \mathrm{p}<.01)$ alanyazında yer alan genel kanaati desteklemektedir (Befort ve Christie, 2001; Lowery vd., 2005). Literatürde benliklerinden memnun olan bireylerin benlik saygılarının yüksek olduğu, söz konusu kişilerin kendiliklerini değiştirme amacı gütmedikleri, kendilik tutarlıklarının yüksek olduğu belirtilmektedir (Elliott, 1986). Bu hususta beden imajı algısının rolü oldukça etkilidir (Hwang, 2017). Dolayısıyla beden imajından memnun olmayan kişilerin değişime sıcak bakacakları, bu sebeple kendilik tutarlılıklarının da düşük düzeyde olduğu ifade edilebilir (Elliott, 1986). 
H3 ve H4 hipotezlerinin sınandığ1 analiz sonuçlarında ise; kadınların beden imaj1 algılarının erkek katılımcılardan daha düşük olmadığı görülmüştür. Söz konusu çıktı geçmiş literatürle örtüşmemektedir. Nitekim önceki araştırmalarda kadınların beden imajı algılarının erkeklere göre daha düşük olduğu ifade edilmektedir (Demarest ve Allen, 2000; Ata, Ludden ve Lally, 2007; Morken, Røysamb, Nilsen ve Karevold, 2019). Bu hususta iletişim fakültesi öğrencilerinin aldıkları formasyon eğitiminin etkili olduğu söylenebilir. İletişim fakültelerinde ilk sınıflardan itibaren dış görünüşün, beden imajının ve diğer psikolojik etmenlerin etkili iletişim kurma noktasında önemli olduğu gerek temel ders kitaplarında (Işık, 2017) gerek uygulamaya yönelik faaliyetlerde sık sık vurgulanmaktadır. Dolayısıyla katılımcılar bu konuda diğer örneklem kümelerine nazaran daha bilinçli bir yapıya sahiptiler. $\mathrm{Bu}$ yüzden öğrenciler aldıkları eğitim sayesinde dolaylı olarak, bu faktörlerin kurmuş oldukları iletişim üzerinde etkili olduğunun bilincindedirler. Dolayısıyla olumsuz beden imajı algısına sahip bir öğrenci gerek mesleğini icra edebilmek adına gerek daha mutlu bir yaşam sürmek için diğer insanlara nazaran beden imajı algısını iyileştirmek amacıyla daha fazla çaba harciyor olabilir. Bu bulgudan hareketle benzer örneklem kümelerine de ilgili eğitimler verilerek, kadınların kendilerine yönelik beden imajı algılarının olumsuz seyretmesinin önüne (dolaylı olarak) geçilebileceği düşünülmektedir. Çünkü sadece mesleki açıdan değil bireyin sosyal çevresiyle kurmuş olduğu iletişimin kalitesi de bir noktada bu faktörlerin etkisi altındadır. İletişim konusunda alınan eğitim sayesinde bireyler daha bilinçli bir düşünce sistemine sahip olabilirler.

H7 hipotezinin analizi sonucunda kadınların erkeklere kıyasla iletişim becerileri hususunda daha yetkin olduğu tespit edilmiştir. İlgili bulgu alan yazında yer alan çıktıları desteklemektedir (Korkut, 1996; Ocak ve Erşen, 2015; Akçam, Kanbay, Işık, 2019; Duğan, Balcı ve Tiryaki, 2017). Dolayısıyla iletişime yönelik formasyon eğitiminin verildiği örneklem kümeleri üzerinde dahi cinsiyet faktörünün iletişim becerileri üzerinde ayırt edici bir etken olduğu görülmüştür.

Araştırmadan elde edilen veriler 1şığında uygulayıcılara ve araştırmacılara aşağıdaki hususlar önerilmektedir;

Beden imajı algısı, iletişim becerilerini geliştirme konusunda etkili bir ön koşul olarak belirmektedir. Dolayısıyla bireyler kurmuş oldukları iletişimin kalitesini artırmak ve söz konusu süreçte daha yetkin olabilmek adına bir noktada da beden imajı algılarını olumlu dairede tutmalıdırlar. Beden imajı algısı birçok dış etmenin etkisi altında olan bir faktör olmakla birlikte birey kendi tercihleri doğrultusunda bu algıyı olumlu yönde değiştirebilecek 
çeşitli adımlar atabilir. Dolayısıyla imkânlar dâhilinde kişi, sahip olduğu algıyı iyileştirebilmek için kendine özgü problemin kaynağını sorgulamalıdır. Bunun yanında dış görünüşüne özen gösterebilir, sağlıklı beslenebilir ve spor yapabilir. Nitekim bu faaliyetler toplumun geneli tarafindan kabul gören, insanın fizyolojik ve psikolojik yapısına olumlu yönde katkı sağlayan aktivitelerdir. $\mathrm{Bu}$ sayede kişilerin etkili iletişim kurma konusunda daha az endişe duyacağı tahmin edilmektedir. Öte yandan net bir çıkarımda bulunmak adına yeni araştırmaların yapılmasına ihtiyaç vardır.

Çevreden alınan geribildirimlerin kişinin bedenine yönelik tutumunu etkilediği bilinmektedir. Bu araştırmadan elde edilen verilere dayanarak sürecin yalnızca bundan ibaret olmadığı, beden imajı algısının da etkili iletişim kurma noktasında önemli bir bileşen olduğu göz önünde bulundurulmalıdır. Dolayısıyla bireylerin beden imajını iyileştirmeye yönelik çabalarının iletişim becerilerini iyileştirme konusunda da önemli olduğu düşünülmektedir. Etkili bir iletişim için bireylerin sürece dair bu geniş çaplı haritanın farkına varması ve bilinçli davranış ve söylemler geliştirmesi avantaj sağlayacaktır.

Araştırmacılar için; kendilik tutarlılığı düzeyleri ile iletişim becerileri arasındaki ilişkiyi daha geniş çapta ele alan araştırmalar gerçekleştirmeleri önerilmektedir. Nitekim bu çalışma kapsamında ulaşılan bulgulara göre kendilik tutarlılı̆̆ 1 düşük ve yüksek seyreden bireylerin iletişim becerileri oldukça benzerdir. Fakat KT düzeyi orta olan katılımcıların bu iki gruptan daha düşük iletişim becerilerine sahip olduğu tespit edilmiştir. Bu durum, KT düzeyi düşük bireylerin kendiliklerinden memnun olmamasıyla ve olumlu yönde benliklerini değiştirmek için farklı söylem stratejileri geliştireceğine yorulmuştur. Takip eden çalışmalarda kendilik tutarlılığı, demografik faktörlerle (özellikle yaş) ve kişisel gelişim dönemleri bağlamında ele alınarak ilgili bağlam zenginleştirilebilir.

Sunulan araştırma çeşitli kısıtlara sahiptir. İlk olarak çalışma evreni; zaman, ulaşım, maliyet ve pandemi kısıtları göz önünde bulundurularak SDÜ İletişim Fakültesi öğrencileri ile sınırlı tutulmuştur. $\mathrm{Bu}$ doğrultuda araştırma nihayetinde ulaşılan bulgular SDÜ İletişim Fakültesi öğrencileri ve benzer gruplar üzerine genellenebilir. Öte yandan covid-19 pandemisi nedeniyle veriler 2019-2020 eğitim-öğretim bahar döneminde online görüşme programları, telefon, e-mail ve sosyal medya araçları ile toplanmıştır. Dolayısıyla çalışma gerçekleştirildiği zaman aralı̆̆ı sebebiyle belirli bir zaman kesitine yönelik bulgular sunmaktadır. Kesitsel araştırma tasarımlarında veriler belirli bir zaman diliminde bir seferde toplanmaktadır. $\mathrm{Bu}$ yönüyle kesitsel araştırma tasarımları anlık fotoğraf çekimine benzetilmektedir (Durna, 2014). Bu doğrultuda araştırmanın kesitsel bir tasarıma sahip 
olması ve verilerin pandemi nedeniyle elektronik ortamlarda toplanması da araştırmanın kısıtları içerisindedir.

Etik Kurul İzin Bilgisi: Araştırma ile ilgili etik onay, Süleyman Demirel Üniversitesi Etik Kurulu'ndan 25.06.2020 tarihinde 92/3 sayılı karar ile alınmış olup, mevcut prosedür etik kararlar çerçevesinde yürütülmüştür.

Yazar Çıkar Çatışması Bilgisi: Yazarlar herhangi bir çıkar çatışması olmadı̆̆ını deklare etmektedir.

Yazar Katkısı: Yazarlar eşit katkıda bulunmuştur ve alfabetik sıraya göre listelenmiştir. 


\section{Kaynakça}

Akçam, A., Kanbay, Y. ve Işık, E. (2019). Hemşirelik Öğrencilerinin İletişim Becerilerinin Değerlendirilmesi. Artvin Çoruh Üniversitesi Uluslararası Sosyal Bilimler Dergisi, 5(2), 74-92.

Allred, R. J., \& Atkin, D. (2020). Cell Phone Addiction, Anxiety, and Willingness to Communicate in Face-to-Face Encounters. Communication Reports, 33(3), 95-106.

Anlı, G., Akın, A., Eker, H. ve Özçelik, B. (2015). Bedeni beğenme ölçeği: geçerlik ve güvenirlik çalışması. The Journal of Academic Social Science Studies, 36(2), 505511.

Arroyo, A. \& Andersen, K. K. (2016). Appearance-related communication and body image outcomes: Fat talk and old talk among mothers and daughters. Journal of Family Communication, 16(2), 95-110.

Ata, R. N., Ludden, A. B. \& Lally, M. M. (2007). The effects of gender and family, friend, and media influences on eating behaviors and body image during adolescence. Journal of Youth and Adolescence, 36(8), 1024-1037.

Banfield, S. S. \& McCabe, M. (2002). An evaluation of the construct of body image. Adolescence, 37(146), 373-393.

Batuş, G., Alver, F., Arık, B., Çoban, B. ve Çı̆̆g, Ü. (2006). Kadife Karanlık. İstanbul: Su Yayınları.

Becker, C. B., Diedrichs, P. C., Jankowski, G. \& Werchan, C. (2013). I'm not just fat, I'm old: has the study of body image overlooked "old talk"? Journal of eating disorders, $1(1), 1-12$.

Befort, C., Hull-Blanks, E. E., Huser, L. \& Sollenberger, S. (2001). Body image, selfesteem, and weight-related criticism from romantic partners. Journal of College Student Development, 42(5), 407-419.

Bienvenu Sr, M. J. (1971). An interpersonal communication inventory. Journal of communication, 21(4), 381-388.

Böke, K. (2014). Örnekleme. K. Böke (Ed.), Sosyal Bilimlerde Araştırma Yöntemleri içinde (104-149), İstanbul: Alfa Basım Yayım Dağıtım. 
Cash, T. E. ve Henry, P. E. (1995). Women's body images: The results of a national survey in the U.S.A. Sex Roles, 33(1/2), 19-28.

Ceyhan, A., Ceyhan, E., \& Kurtyilmaz, Y. (2012). The effect of body image satisfaction on problematic internet use through social support, problem solving skills and depression. The Online Journal of Counselling and Education, 1(3), 83-95.

Clark, L. \& Tiggemann, M. (2007). Sociocultural influences and body image in 9 to 12year-old girls: The role of appearance schemas. Journal of Clinical Child and Adolescent Psychology, 36(1), 76-86.

Cusumano, D. L. \& Thompson, J. K. (2001). Media influence and body image in 811-year-old boys and girls: A preliminary report on the multidimensional media influence scale. International Journal of Eating Disorders, 29(1), 37-44.

Çuhadaroğlu, F. (1986). Adolesanlarda benlik saygısı. Doktora tezi, Hacettepe Üniversitesi, Sosyal Bilimler Enstitüsü, Ankara.

Demarest, J. \& Allen, R. (2000). Body image: Gender, ethnic, and age differences. The Journal of social psychology, 140(4), 465-472.

Donnellan, M. B., Trzesniewski, K. H., Robins, R. W., Moffitt, T. E. \& Caspi, A. (2005). Low selfesteem is related to aggression, antisocial behavior, and delinquency. Psychological Science, 16(4), 328-335.

Duğan, Ö., Balcı, E. V. \& Tiryaki, S. (2017). Yabancı uyruklu ve Türk öğrencilerin iletişim becerilerinin karşılaştırılması: Uşak Üniversitesi örneği. Sobider, 4(13), 227-242.

Durna, T. (2014). Nedensellik ve araştırma tasarımları. K. Böke (Ed.), Sosyal Bilimlerde Araştırma Yöntemleri İçinde (153-197). İstanbul: Alfa Basım Yayım Dağıtım.

Elliott, G. (1986). Self-Esteem and self-consistency: A Theoretical and Empirical link between two primary motivations. Social Psychology, 49(3), 207-218.

Engel, M. (1959). The stability of the self-concept in adolescence. The Journal of Abnormal and Social Psychology, 58(2), 211-215.

Erikson, E. H. (1956). The problem of ego identity. Journal of the American Psychoanalytic Association, 4(1), 56-121.

Ersanlı, K. ve Balcı, S. (1998). İletişim becerileri envanterinin geliştirilmesi: Geçerlik ve güvenirlik çalışması. Türk Psikolojik Danışma ve Rehberlik Dergisi, 2(10), 7-12. 
Foustanos, A., Pantazi, L., \& Zavrides, H. (2007). Representations in plastic surgery: the impact of self-image and self-confidence in the work environment. Aesthetic plastic surgery, 31(5), 435-442.

Gardner, R. M. (1996). Methodological issues in assessment of the perceptual component of body image disturbance. British Journal of Psychology, 87(2), 327-337.

Giananti, A. (2020). I know how I know: perception, self-awareness, self-knowledge. Synthese. Advanced online publication. https://doi.org/10.1007/s11229-020-02726-9

Goffman, E. (2014). Günlük yaşamda benliğin sunumu. Çev: Barış Cezar, (3. Baskı). İstanbul: Metis Yayınları.

Grogan, S. (2006). Body image and health: Contemporary perspectives. Journal of health psychology, 11(4), 523-530.

Güler, Ş. ve Sezgin, M. (2020). Benlik saygısı ve e-katılım ilişkisi: Twitter ekseninde akademisyenlere yönelik bir uygulama. Pamukkale Üniversitesi Eğitim Fakültesi Dergisi, 49, 413-438.

Hair, J. F., Black, W. C., Babin, B. J., Anderson, R. E. \& Tatham, R. L. (2014). Multivariate Data Analysis. (Seventh Edition). Pearson Education Limited.

Hattie, J. (2014). Self-concept. New York - London: Psychology Press.

Hwang, R. H. (2017). Self-esteem, body image and factors influencing on depression of infertile women. Journal of Digital Convergence, 15(10), 537-549.

Işı, M. (2017). Sizinle İletişebilir miyiz? Konya: Eğitim Yayınevi.

Jacobson, E. (2004). Kendilik ve nesne dünyası. S. Yazgan (Çev.),. İstanbul: Metis Yayınları.

James, W. (1983). The principles of psychology. Cambridge: Harvard University Press.

Kichler, J. C. \& Crowther, J. H. (2009). Young girls' eating attitudes and body image dissatisfaction: Associations with communication and modeling. The Journal of Early Adolescence, 29(2), 212-232.

Korkmaz, M. (1996). Yetişkin örneklem için bir benlik saygısı ölçeğinin güvenirlik ve geçerlik çalışması. Yüksek Lisans Tezi, Ege Üniversitesi Sosyal Bilimler Enstitüsü, İzmir. 
Korkut, F. (2016). İletişim becerilerini değerlendirme ölçeğinin geliştirilmesi: güvenirlik ve geçerlik çalışmaları. Türk Psikolojik Danışma ve Rehberlik Dergisi, 2(7), 18-23.

Liberman, Z., Woodward, A. L., Keysar, B. \& Kinzler, K. D. (2017). Exposure to multiple languages enhances communication skills in infancy. Developmental science, 20(1), $1-11$.

Lowery, S. E., Kurpius, S. E. R., Befort, C., Blanks, E. H., Sollenberger, S., Nicpon, M. F. \& Huser, L. (2005). Body image, self-esteem, and health-related behaviors among male and female first year college students. Journal of College Student Development, 46(6), 612-623.

Marsh, H. W. \& Shavelson, R. (1985). Self-concept: Its multifaceted, hierarchical structure. Educational psychologist, 20(3), 107-123.

Morken, I. S., Røysamb, E., Nilsen, W. \& Karevold, E. B. (2019). Body dissatisfaction and depressive symptoms on the threshold to adolescence: Examining gender differences in depressive symptoms and the 1mpact of social support. The Journal of Early Adolescence, 39(6), 814-838.

Neiss, M. B., Sedikides, C., \& Stevenson, J. (2002). Self-esteem: a behavioural genetic perspective. European Journal of Personality, 16(5), 351-367.

Ocak, G. ve Erşen, B. Z. (2019). Öğretmen adaylarının iletişim becerileri algılarının incelenmesi. Mehmet Akif Ersoy Üniversitesi Eğitim Fakültesi Dergisi, 33, 1 - 19.

Pole, M., Crowther, J. H. \& Schell, J. (2004). Body dissatisfaction in married women: The role of spousal influence and marital communication patterns. Body image, 1(3), 267-278.

Razı, G. S., Kuzu, A., Yıldız, A. N., Ocakcı, A. F., \& Arifoğlu, B. Ç. (2009). Çalışan gençlerde benlik saygısı, iletişim becerileri ve stresle baş etme. TAF Preventive Medicine Bulletin, 8(1), 17-26.

Righetti, F. \& Visserman, M. (2018). I gave too much: Low self-esteem and the regret of sacrifices. Social Psychological and Personality Science, 9(4), 453-460.

Rosenberg, M. (1965). Society and the adolescent self-image. NJ: Princeton University Press.

Rosenberg, M. (1979). Conceiving the Self. New York: Basic Books. 
Rosenberg, M. (1989). Self-concept research: A historical overview. Social forces, 68(1), 34-44.

Rubin, R. B. \& Martin, M. M. (1994). Development of a measure of interpersonal communication competence. Communication Research Reports, 11(1), 33-44.

Rumsey, N., \& Harcourt, D. (2004). Body image and disfigurement: issues and interventions. Body image, 1(1), 83-97.

Samuel, M. \& O. Ethelbert, L. (2015). The Relevance And Significance Of Correlation In Social Science Research. International Journal of Sociology and Anthropology Research, 1(3), 22-28.

Schmitt, D. P. \& Allik, J. (2005). simultaneous administration of the rosenberg self-esteem scale in 53 nations: exploring the universal and culture-specific features of global self esteem. Journal of Personality And Social Psychology, 89(4), 623-642.

Schooler, D., Ward, L. M., Merriwether, A. \& Caruthers, A. (2004). Who's that girl: Television's role in the body image development of young white and black women. Psychology of women quarterly, 28(1), 38-47.

Sezgin, M., \& Güler, Ş. The role of digital feedback on the self-esteem of digital natives. Türkiye İletişim Araştırmaları Dergisi, (35), 46-62.

Shavelson, R. J., Hubner, J. J. \& Stanton, G. C. (1976). Validation of construct interpretations. Review of Educational Research, 46, 407-441.

Slade, P. D. (1994). What is body image? Behaviour Research and Therapy, 32(5), 497-502.

Slater, A. \& Tiggemann, M. (2016). Little girls in a grown up world: Exposure to sexualized media, internalization of sexualization messages, and body image in 6-9 year-old girls. Body image, 18, 19-22.

Stewart, J., Zediker, K. \& Witteborn, S. (2005). Together: Communicating interpersonally: a social construction approach, 6th edn. Los Angeles, CA: Roxbury

Tylka, T. L. \& Wood-Barcalow, N. L. (2015). The Body Appreciation Scale-2: item refinement and psychometric evaluation. Body image, 12(January), 53-67. https://doi.org/10.1016/j.bodyim.2014.09.006.

Ünal, S. (2012). Evaluating the effect of self-awareness and communication techniques on nurses' assertiveness and self-esteem. Contemporary nurse, 43(1), 90-98. 
Vani, M. F., Pila, E., Willson, E., \& Sabiston, C. M. (2020). Body-related embarrassment: The overlooked self-conscious emotion. Body image, 32(March), 14-23. https://doi.org/10.1016/j.bodyim.2019.10.007.

Vatankhah, H., Daryabari, D., Ghadami, V., \& Naderifar, N. (2013). The effectiveness of communication skills training on self-concept, self-esteem and assertiveness of female students in guidance school in Rasht. Procedia-Social and Behavioral Sciences, 84, 885-889.

Wiemann, J. (2003). Foreword. In J. Greene \& B. Burleson (Eds), In Handbook of communication and social interaction skills. Mahwah, NJ: Lawrence Erlbaum.

Woodrow-Keys, E. (2006). The effects of body image on career decision making, selfefficacy and assertiveness in female athletes and non-athletes (Doctoral dissertation, Marshall University Libraries).

Zivnuska, S., Carlson, J. R., Carlson, D. S., Harris, R. B. \& Harris, K. J. (2019). Social media addiction and social media reactions: The implications for job performance. The Journal of social psychology, 159(6), 746-760. 


\title{
The Effects of Self on Words: An Investigation of the Relationships between Self
}

\section{Consistency, Body Image and Communication Skills Specific for Students of the}

\section{Communication Department}

\author{
Murat SEZGIN* Şakir GÜLER**
}

- Received: $28.08 .2020 \bullet$ Accepted: 25.11.2020 • Online First: 25.11.2020

\begin{abstract}
The aim of this study is to explore the effect of "body image perception" and "self-consistency" on communication skills. The study was patterned in a general screening model style, and the data was collected cross-sectional. A sample of 308 participants was determined using the simple random sampling method. According to the results, the participants' body image perception affects communication skills by $24.2 \%$, and the participants' self-consistency affects their communication skills by $2.3 \%$. A positively significant relationship is found between body image and selfconsistency. It has been found that women are more competent in terms of communication skills than men. This study examines communication skills extensively in terms of self-consistency and body image. In this aspect, it offers a new look at the literature. The results show that discourses from the outside environment affect body image, but body image also affects communication skills. The current findings contribute to the emerging literature as it addresses the impact of body image on communication skills.
\end{abstract}

Keywords: body image, self-consistency, communication skills, self-esteem, communication education.

\section{Cited:}

Sezgin, M., \& Güler, Ş. (2020). The effects of self on words: an investigation of the relationships between self-consistency, body image, and communication skills specific for students of the communication department. Pamukkale University Journal of Education, 52, 206-234 doi:10.9779.pauefd.787237

\footnotetext{
* Assoc. Prof. Dr., Uşak University, Department of Public Relations and Advertising, Orcid: 0000-0003-2200-3301 murat.sezgin@usak.edu.tr

** Res. Assist., Suleyman Demirel University, Department of Public Relations and Publicity, Orcid: 0000-0002-7365-6639, sakirguler@yandex.com.
} 


\section{Introduction}

The twenty-first century came to the fore as a process in which communication rapidly transformed and became increasingly complex. While the developing technology and the transferred cultural heritage ${ }^{1}$ facilitate the communication process in quantity, on the other hand, some negative developments ${ }^{2}$ caused by information communication technologies threaten the healthy communication process (Zivnuska, Carlson, Carlson, Harris \& Harris, 2019). For this reason, in the century in which we live, people should technically know the phenomenon of communication and develop their skills in this regard (Ersanlı and Balc1, 1998). According to Iş1k (2017), communication is when images of feelings, thoughts, and actions are transferred from source to receiver through various channels, verbally, and nonverbally. Individuals aim to communicate with the external environment from the first moments of their birth (Ersanl1 \& Balc1, 1998). Moreover, elements that interact or are exposed even in childhood affect the person's communication skills in the future (Liberman, Woodward, Keysar \& Kinzler, 2017). Communication skills play an important role in personal life, both in building and sustainability of the social world and improving the quality of life (Wiemann, 2003; Stewart, Zediker \& Witteborn, 2005). Therefore, a study that addresses the contexts in which communication skills are related is important today. Body image perception and self-perception are also very important contexts that relate to communication skills.

Studies show that individuals with negative body images avoid social situations and behave more timidly in communicating (Foustanos, Pantazi \& Zavrides, 2007; Vani, Pila, Wilson \& Sabiston, 2020). Simultaneously, communication skills are an important factor in the self's presentation to the external environment. Individuals should have various communication skills to positively affect others' impression while presenting information about themselves to the outside environment (Goffman, 2014; Ünal, 2011). Moreover,

\footnotetext{
${ }^{1}$ Developments recorded in "voice and written" symbols for the purpose of communication are passed on to future generations as a cultural heritage. Thus, many advances have been made in speech and writing languages so far. Communication processes are positively affected in a similar way as these cultural accumulations also mediate the development of intellectual concepts.

${ }^{2}$ With the development of Information Communication Technologies, people have had the opportunity to communicate faster than before using mobile phones, social media and other communication devices without time and space commitment. On the other hand, these technologies threaten the healthy communication process, as they also mediate the spread of disinformative messages, the source of which is unclear. In addition, the use of communication devices such as social media causes individuals to become addicted to various applications against their will. Therefore, while individuals have the opportunity to communicate without time and space limitations due to these innovations, problems may occur in their ability to communicate face to face on the other hand (Allred \& Atkin, 2020).
} 
communication skills and the concept of self are thought to have a mutual interaction. As a matter of fact, research has shown that self-perceptions of individuals who develop communication skills through various training also change positively (Ünal, 2011).

For this reason, in order to understand the relationship between perceptions of "selfconcept" and "body image" with communication skills, it is necessary to take a closer look at the related concepts.

The concept of self is generally defined as the individual's perceptions of himself (Marsh \& Shavelson, 1985). In another approach, the self is considered as the whole of feelings and thoughts attributed to individuality (Rosenberg, 1989). In this context, the individual's contacts with the external environment are essential for the formation of these perceptions (Shavelson, Hubner \& Stanton, 1976). As a result of this situation, the individual interacting with the external environment also makes various self-depictions on any emotion or action from an internal perspective. Marsh and Shavelson (1985) state that such descriptions such as "I am good at this" and "I am a very happy person" also shape the self at this point.

Sherif and Cantril named the concept of self as ego. Allport named the concept of self as proprium (cited in Korkmaz, 1996). While Erikson (1956) named the concept of self as ego identity, William James (1983), the pioneer of the concept, treated the knowing self as "I" and the known self as "me". Oyserman, Elmore, and Smith (2012) state that researchers in the field interpret the concept of the self as both a situation and a result of shaping situations and actions. Therefore, the explanations related to the concept of selfcontained in the literature extend to a wide area.

Addressing the definitions of the self in the literature, Hattie (2014) mentions that instead of defining this concept in various dimensions, it is necessary to make sense of the self by revealing the other factors it interacts with. Hattie (2014) exemplified the way physicists handle the concept of electricity. Hattie stated that according to a physicist, defining electricity is absurd and that electricity can only be made meaningful to individuals by exploring its functional aspects and revealing the contexts in which it is related. Rather than defining electricity, issues such as how the concept should be used, how it reacts to other variables, and why it is valuable to know the features of the concept are also valid for the self-concept. Within the scope of this research, the effect of self-consistency, which is one of the two basic components of the self-concept (Elliott, 1986) on communication skills, will be investigated. 
Before proceeding to the definition of "self-consistency," it should be noted that as individuals discover the world of objects, they experience the reality of the external world with the consciousness of the "other." Due to the newly formed self-representations, the self-concept does not consistently form in the infancy and childhood years of the individual's birth. On the other hand, self-images assuming a style over time and exhibiting behaviors in this direction are considered "self-consistency" (Jacobson, 2004). Self-consistency is the consistency and integrity of one's self-evaluations and self. For this reason, an experience that is incompatible with the self is not easily assimilated because it is not consistent, and the person enters a difficult repair process in such cases (Elliott, 1986).

Self-consistency is one of the two primary sources of motivation (motives) necessary for the protection and maintenance of the self-concept. It protects the self-image of the individual against changes and helps to maintain the self. Another self-motivation is the concept of self-esteem. Self-esteem motivates people to trust, value, and respect themselves (Elliott, 1986; Korkmaz, 1996). Self-esteem and self-consistency, which are two essential components for protecting and maintaining the self-concept, have a very strong positive relationship. But according to the pattern of current research, research hypotheses will be built over self-consistency within the study's scope.

In the strong positive relationship between self-esteem and self-consistency, self-esteem affects self-consistency (Elliott, 1986). Studies in the literature have revealed that people with low self-esteem are unhappy with their identity and feel incomplete and worthless. (Donnellan, Trzesniewski, Robins, Moffitt \& Caspi, 2005; Righetti, Visserman, 2018). Therefore, individuals with low self-esteem are not satisfied with their self-image, and they are open to change. Therefore, the self-concepts of these individuals tend to be less consistent (Elliott, 1986). At this point, individuals should be aware of themselves and positively improve their current situation (Ünal, 2011).

As a matter of fact, it is not enough for a person to change his or her perceptions of himself or herself to change his or her self positively. Basic components of the self, such as self-awareness and self-esteem, are affected by both the external environment (Shavelson, Hubner \& Stanton, 1976; Sezgin \& Güler, 2020) and the internal dynamics of the person (e.g., genetic factors, perceptions, etc.) (Neiss, Sedikides \& Stevenson, 2002; Giananti, 2020). Therefore, the impressions of the external environment are important in selfperception. In this regard, Goffman (2014) states that an individual can manage his or her impressions of his or her self "through a communication channel" in the social settings in 
which he or she is involved. Therefore, for the individual to manage these impressions through communication, he/she must use and learn various communication skills (Ünal, 2011). Goffman (2014) refers to spreading and managing the self's impressions, especially through verbal symbols under the title of "impression given." Goffman assumes that individuals can determine their attitudes about the external environment by speaking or through other verbal symbols.

In this context, communication skills will also benefit individuals with low selfconsistency and self-esteem to improve their self-esteem. According to the research conducted by Vatankhah, Daryabari, Ghadami \& Naderifar (2013) on secondary school students, it was concluded that the students who received 90 minutes of communication skills training per week for eight weeks significantly increased their self-esteem compared to other students in the control group. According to another study conducted by Ünal (2011) on university students, when individuals develop communication skills such as listening to the criticism directed at them, expressing their opinions and making demands from others or rejecting the demands made when necessary, individuals' self-perceptions also change positively (Ünal, 2011) similarly, as individuals' communication skills increase, their selfconfidence and optimistic attitudes increase (Razı et al., 2009).

For this reason, the first hypothesis (H1) of the study was created by assuming that individuals with low self-esteem and self-consistency would also need to improve their communication skills ${ }^{3}$ to change.

Individuals with high self-esteem, on the contrary, are satisfied with the self they have. Aware of their weaknesses, these people live a life without feeling the need to heal them and do not seek to change the self they have (Elliott, 1986). In this context, individuals with high self-esteem are expected to be satisfied with their 'consistent self' (Engel, 1959). Accordingly, a positive relationship is expected between self-esteem and self-consistency. When the studies in the literature are examined, the role of external appearance and body image is quite important in high self-esteem (Befort \& Christie, 2001; Lowery et al., 2005;

\footnotetext{
3 Within the scope of this study, communication skills express the individual's ability to express his feelings and thoughts openly, express his / her own characteristics freely, self-confidence, communication dominance over others and social comfort (Bienvenu, 1971; Rubin \& Martin, 1994). The concept of communication means that the individual transmits the message he / she wants to convey to the receiver through various channels. Therefore, the main purpose of communication skills is that the individual can successfully convey the message he / she wants to convey to the recipient. Therefore, concepts have a strong interaction in terms of meaning.
} 
Hwang, 2017). Therefore, H2, the second hypothesis of the research, was formed on the basis of this conceptual basis.

The concept of body image was first defined in the monograph The Image and Appearance of the Human Body as "the photograph of our body formed in our minds" (Schilder cited in Slade, 1994). In the following periods, the definition of body image has expanded to include our feelings and perceptions towards the photograph in our mind (Grogan, 2006; Slade, 1994). According to the studies conducted until 1996, studies to distinguish the two components, which include feelings and attitudes towards body image, were insufficient (Gardner \& Rick, 1996). It was stated that components related to body image were more in the following periods. Issues such as perception, attitude, cognition, behavior, and attraction, fear of obesity, body disorder, body dissatisfaction, and diet were evaluated within this scope (Banfield \& McCabe, 2002). Although these dimensions extend to a wide range, it is seen that until 2006, studies on body image mostly focused on dissatisfaction with the body and the desire to be weak (Grogan, 2006).

Studies dealing with body image in terms of demographic variables, age, race, and gender themed studies are at the forefront. In the context of gender, the general opinion in the literature is that women perceive themselves as having a more negative image than they are, while men are more satisfied with their current appearance than women (Ata, Ludden \& Lally, 2007; Demarest \& Allen, 2000; Morken, Røysamb, Nilsen \& Karevold, 2019). Accordingly, it can be assumed that men's and women's body image perceptions differ (H3$\mathrm{H} 4)$.

In terms of ethnicity (race), more American-based studies have been conducted. In these studies, it is reported that African American individuals' attitudes towards their bodies are more positive and consistent than other groups (Demarest \& Allen, 2000; Miller, Gleaves, Hirsch, Green, Snow \& Corbett, 2000; Schooler, Ward, Merriwether \& Caruthers, 2004).

In studies dealing with body image in terms of age, the first thing that draws attention is that women are preferred more frequently as a sample (Cusumano \& Thompson, 2001). It is noted that body dissatisfaction with aging gradually increases until the age of 50, but decreases after the age of 50 (Becker, Diedrichs, Jankowski \& Werchan, 2013). In studies conducted on earlier age groups, such as the 9-18 age range within the scope of body image, the effects of "traditional and new media" on body image were more often questioned. According to the results of Clark and Tiggemann's (2007) research on girls 
going to primary school (n265), Peer Conversations, TV shows and tabloids play an important role in this context in the formation of body dissatisfaction. Exposure to negative media messages causes serious damage to individuals' perception of body image, especially in lower age groups (6-9 years) (Slater \& Tiggemann, 2016). Therefore, a change in body image perception can be expected depending on age (H5).

On the other hand, when research on body image is examined, there is no research model in which body image perception and communication skills are considered together. But it is possible to come across various studies in which some of the sub-factors that can be evaluated within the scope of communication skills are examined in terms of body image. In order to see the interaction between concepts more closely, it is necessary to mention these studies.

According to a study conducted by Ceyhan, Ceyhan \& Kuryilmaz (2012) on 492 Turkish students, body image perception significantly impacts problem-solving skills. In this direction, it is stated that individuals who are satisfied with their body image have better problem-solving skills. On the other hand, it is emphasized that students who are not satisfied with their body image may experience more symptoms of depression. In WoodrowKeys ' (2006) study of University women, it is stated that individuals who play regular sports have a more positive perception of body image. Their perception of body image is a significant factor in their being sociable. The initiative is considered as an important communication skill in terms of individuals freely expressing their ideas in the social environment and managing the communication process (Bienvenu, 1971; Rubin \& Martin, 1994). In the compilation by Rumsey and Harcourt (2004), it is seen that individuals who have negative body image and have various disadvantages in terms of appearance (congenital or subsequent deformations in body limbs, diseases, etc.) have problems in social interaction, are hesitant to meet new people and have difficulty in developing longterm relationships. Accordingly, some individuals may even undergo surgical operations to have a more positive body image perception. A study conducted by Foustanos, Pantazi, and Zavrides (2007) on this condition concluded that after plastic surgery, individuals have a more positive perception of body image than before, and their self-confidence increases. Within the same study's scope, the researchers stated that when other variables were kept constant, the perceived body image positively affected interpersonal relationships, and individuals with positive body image naturally increased their self-confidence. Selfconfidence is also considered within the scope of communication skills (Bienvenu, 1971; 
Rubin \& Martin, 1994). However, this study by Foustanos, Pantazi \& Zavrides (2007) states that besides the perceived body image, positive feedback from the external environment also positively affects interpersonal relationships.

Therefore, research into the impact of body image on communication skills in the literature is quite limited. Also, these studies focus on specific communication skills rather than comprehensively addressing communication skills. For this reason, no model has been found that directly questions the impact of body image on communication skills.

Studies that deal with "body image" and "communication" together mostly focus on the effect of feedback received from the external environment on body image (Kichler \& Crowther, 2009; Pole, Crowther \& Schell, 2004).

For example, Kichler and Crowther (2009) evaluated feedback from the external environment as a communication element in their research on female students in early adolescence. They examined the impact of this feedback on the body image of schoolgirls. Therefore, they found a significant relationship between female students ' dissatisfaction with their bodies and the negative discourses from the environment. Kichler and Crowther (2009) noted that peers' negative feedback was more effective than feedback from family when participants were dissatisfied with their bodies.

Similarly, another study found that married women's feedback from their partners affected their body dissatisfaction (Pole, Crowther \& Schell, 2004). As can be seen from these studies, in models where the concept of "communication" is associated with body image in the literature, communication is more often encoded as "feedback from the environment." The limited literature examining the effect of body image perception on communication skills shows that body image impacts communication skills.

As part of this research, the effect of perceived body image (BIP) on personal communication skills (CS) is investigated (H6). The study comprehensively addresses communication skills. It is assumed that this aspect will contribute to the field.

Therefore, before proceeding to the application section, it is necessary to briefly address the concept of "communication skills," which is considered to be related to the perception of image and the concept of self.

Communication skills are briefly summarized as effective listening and responsiveness (Korkut, 1996). Communication skills are shaped by the experience gained. The purpose of communication skills is to ensure that the established communication 
healthily takes place. In the literature, it is emphasized that there are gender-centered differences in learning communication skills. It is reported that women express their feelings and thoughts more clearly and exhibit more social and sensitive attitudes than men (Korkut, 1996). Therefore, it can be argued that women's communication skills are better than men's (H7).

In this study, communication skills were determined by reference to interpersonal communication inventories developed by Bienvenu (1971) and Rubin \& Martin (1994). Therefore, the communication skills that the study refers to include eleven basic elements as content. The first is the concept of a healthy and adequate self that allows people to communicate with others. This is followed by the ability to be a good listener, the selfsacrifice to express feelings and thoughts clearly (self-expression), the desire to express oneself to others correctly and freely (expression), environmental dominance, friendliness, interaction management, focus on the other, self-confidence, social titles such as comfort and empathy (Bienvenu, 1971; Rubin \& Martin, 1994). However, since the communication skills scale used in the study is considered a single factor, these eleven skills have been conceptualized as a communication skill title.

The research aims to question the role of body image perception and self-consistency on communication skills. As a matter of fact, students of the Faculty of communication need to be effective communicators both in their professional life and in their social life. In this context, the role of self-consistency and body image perceptions on communication skills of communication faculty students will be examined in the application part of the study. The hypotheses of the study are as follows:

- H1: Self-consistency affects communication skills ${ }^{4}$.

- H2: there is a significant positive relationship between participants ' body image perceptions and their self-consistency.

- H3: participants ' body image perceptions differ according to their gender.

- H4: Body image perceptions of women have a lower average than male participants.

\footnotetext{
${ }^{4}$ As part of this research, communication skills express the ability of a person to clearly express their feelings and thoughts, freely express their self-characteristics, self-confidence, communication dominance over their interlocutors and social comfort (Bienvenu, 1971; Rubin \& Martin, 1994). The concept of communication, on the other hand, is used in the sense that "the individual transmits the message he wants to convey to the recipient through various channels". Therefore, the main goal in communication skills is to successfully communicate the message that the individual wants to deliver to the recipient to the target. Therefore, concepts have a strong interaction in terms of meaning.
} 
- H5: Participants' body image perceptions differ according to their ages.

- H6: Participants' body image perceptions have a significant effect on communication skills.

- H7: Communication skills differ by gender.

\section{Method}

The research was built on the relational screening model between variables within the quantitative (survey) method. Research is carried out on a sample selected from among many units in the population in scanning models. The aim is to obtain information about the general population, with the study's result (Karasar, 1984; Punch, 2013; Neuman, 2014). Data were collected by survey technique, one of the quantitative research methods. Details about the study group of the research, data collection tools, and statistical tests where the data are analyzed are given in this section.

\section{Participants}

Communication faculty students constitute the abstract population of the study. On the other hand, the achievable target/study population (Karasar, 1984) consists of Süleyman Demirel University Faculty of Communication students. As of the 2019-2020 academic year, there are three active departments in SDU Faculty of Communication, Public Relations and Publicity, Journalism, Radio-Television and Cinema, and 1232 students studying in these departments. Three hundred twenty-eight students were selected as a sample (voluntarily) using the simple random sample method among the study population based on the students' school numbers. In the simple random sampling method, the boundaries of the study population must be known clearly. On the other hand, each unit in the universe has an equal chance of being selected for sampling (Böke, 2014). During the data analysis, 20 questionnaires that were found to be filled in inattentively were excluded from the study. The necessary analyzes were carried out on a sample set of 308 people. 


\section{Data Collection Tools}

The data were collected by survey technique, one of the quantitative research methods. The related research questionnaire consists of the question items included in the Interpersonal Communication Competence Scale (ICCS), Self-consistency Scale (SCS), Body Appreciation Scale (BAS), and Personal Information Form (PIF).

\section{Interpersonal Communication Competence Scale-ICCS}

The Interpersonal Communication Competence Scale (ICCS) was developed by Rubin and Martin (1994) as a Likert-style scale on 477 students. ICCS was originally developed with 60 -item questions. The reliability value of this form is $\alpha=.77$. The reliability value of the 30 -item form of the scale is $\alpha=.87$. The reliability values of the sub-dimensions range from $\alpha=.41$ to $\alpha=.72$. Therefore, the authors recommend using the scale as a single dimension without dividing it into sub-dimensions. The validity of the scale was tested with the concordance validity method $(\mathrm{r}=.52, \mathrm{p}<.01)$, and the coefficient alpha reliability was $\alpha=$ .71 (Rubin \& Martin, 1994). Within the scope of this research, the reliability coefficient of the scale is $\alpha=.82$. Explanatory factor analysis (EFA) and confirmatory factor analysis (CFA) were performed to confirm the construct validity of the scale. During the EFA, five items incompatible with the whole of ICCS were dropped. CFA values showed that the current structure of the scale has an ideal fit. $\left(\chi^{2} / \mathrm{sd}=4.244\right.$, GFI=.92, CFI=.90, TLI=.90, $\mathrm{NFI}=.90, \mathrm{IFI}=.90, \mathrm{RMSEA}=.01$, and $\mathrm{SRMR}=.01)$.

Self-Consistency Scale (SCS)

SCS is a sub-dimension of self-esteem scale (RSE) developed by Rosenberg (1965). The self-esteem scale consists of 63 items in total and has 12 sub-dimensions. Test-retest coefficient for the overall RSE ranges from $r=.82$ to .88 . The level of reliability varies between $\alpha=.77-.88$. The validity and reliability studies of the scale were conducted by Çuhadaroğlu (1986), and the test-retest coefficient was $=.48-.79$. In a study carried out by Schmitt and Allik (2005), it was reported that the scale was a universal scale by testing the compatibility of RSE with universal culture.

As part of this research, the reliability value $\alpha=$ for the sub-dimension of "continuity of the concept of self," which is called "self-consistency," was calculated as .75. Factor Analysis confirmed the validity of the scale. During factor analysis, a substance that was found not to match the whole was removed from the scale. The total variance explained by the scale was calculated as $58,473 \%$. 
The Body Appreciation Scale-2 was finally developed by Tylka and Wood-Barcalow (2015, p.58) as a Likert-style scale on 820 female and 767 male participants with the rearrangement of the 13-item Body Appreciation Scale (Original Title: Body Appreciation Scale -BAS). The items are positively coded. The reliability coefficient of the 10-item BAS-2 scale was determined as $\alpha=.94$ and $\alpha=.93$ for female and male participants. The correlation coefficient for test-retest reliability was $=.90$. Validity and reliability studies of the scale were carried out by Anlı, Akın, Eker, and Özçelik (2015) using internal consistency analysis and CFA methods. As a result, the reliability value of the scale was calculated as $\alpha=.88$, DFA values were $\mathrm{x}^{2}=72.46, \mathrm{sd}=33, \mathrm{RMSEA}=.077, \mathrm{CFI}=.98, \mathrm{IFI}=.98, \mathrm{RFI}=.95$, GFI $=.93$, SRMR. $=.045$.

Within this research scope, the reliability value for the BAS -2 tool was calculated as $\alpha=.89$. The total variance explained by BAS -2 within the scope of this research is $54,090 \%$.

\section{Personal Information Form (PIF)}

In the $\mathrm{KBF}$, there are questions about socio-demographic information such as age, gender, number of siblings, place where they spend most of their lives, and their economic income.

\section{Research Model}

The research model, which describes the direction and type of hypotheses in line with the purpose of the research, is as shown in Figure 1.

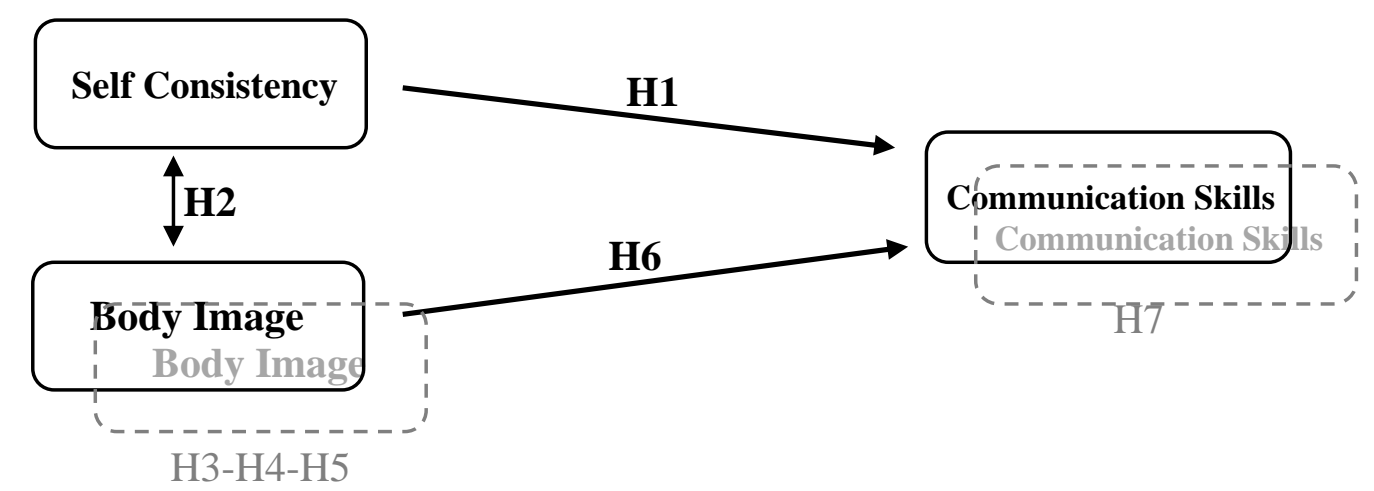

Figure 1. Research Model 


\section{Procedure}

Research data were collected in the spring semester of the 2019-2020 academic year. Participation in the research is voluntary by informing the participants about the research. Ethical approval regarding the research was obtained from Suleyman Demirel University Ethics Committee on 25.06.2020 with the decision number 92/3, and the current procedure was carried out within the framework of ethical decisions. On the other hand, participants were told that they could leave the questions unanswered if they did not want to answer, especially the demographic questions. The application took approximately 6-14 minutes for each participant.

\section{Data Analysis}

As shown in Table 1, kurtosis values of research variables $(n>30)$ vary between -0.28 and +0.19 , and skewness values vary between -0.66 and +0.12 . According to Hair, Black, Babin, Anderson, and Tatham (2014), kurtosis and skewness values of \pm 1.0 indicate that the data are distributed normally. Therefore, the research hypotheses were tested with parametric tests using the SPSS 24.0 package program. While the relational hypotheses were analyzed by calculating the Pearson Correlation coefficient, the impact hypotheses were tested with simple linear regression analysis. The hypotheses dealing with the differentiation between variables were tested with ANOVA and Independent Samples t-Tests. On the other hand, the data regarding the participants' demographic status were described by Frequency Analysis.

Table 1. Mean, Standard Deviation, Kurtosis and Skewness Values for Research Variables

\begin{tabular}{lccccccccc}
\hline & & & & & \multicolumn{2}{c}{ Skewness } & \multicolumn{2}{c}{ Kurtosis } \\
\cline { 6 - 10 } & Min. & Max. & $\overline{\mathrm{x}}$ & $\mathrm{Sd}$ & \multicolumn{2}{c}{ Statistic Std. E. Statistic Std. E. } \\
\hline Communication & 2.72 & 5.00 & 3.8697 & .42731 & .039 & .139 & -.210 & .277 \\
Skills & & & & & & & & \\
Self-Consistency & 1.00 & 5.00 & 2.9852 & .91506 & .125 & .139 & -.285 & .277 \\
Body Image & 2.22 & 5.00 & 4.1166 & .66350 & -.666 & .139 & .194 & .277 \\
\hline
\end{tabular}




\section{Results}

Results regarding the participants' socio-demographic status such as age, gender, number of siblings, place where they spend most of their lives, and their economic income are shown in Table 2.

Table 2. Results Regarding the Socio-Demographic Characteristics of the Participants

\begin{tabular}{|c|c|c|c|}
\hline & & Frequency & Percentage \\
\hline & $18-20$ & 81 & 26,3 \\
\hline & $21-23$ & 153 & 49,7 \\
\hline \multirow[t]{5}{*}{ Age } & $24-26$ & 56 & 18,2 \\
\hline & $27-29$ & 6 & 1,9 \\
\hline & 30 and + & 12 & 3,9 \\
\hline & Total & 308 & 100,0 \\
\hline & Female & 156 & 50,6 \\
\hline \multirow[t]{5}{*}{ Gender } & Male & 152 & 49,4 \\
\hline & Total & 308 & 100,0 \\
\hline & I have not got brother or sister & 21 & 6,8 \\
\hline & We are 2 siblings & 131 & 42,5 \\
\hline & We are 3 siblings & 80 & 26,0 \\
\hline \multirow[t]{4}{*}{ Number of Siblings } & We are 4 siblings & 34 & 11,0 \\
\hline & We are $5-7$ siblings & 32 & 10,4 \\
\hline & 8 and + & 10 & 3,2 \\
\hline & Total & 308 & 100,0 \\
\hline The Place Where & City & 185 & 60,1 \\
\hline They Spent Most of & County & 92 & 29,9 \\
\hline \multirow[t]{7}{*}{ Their Lives } & Town & 5 & 1,6 \\
\hline & Village & 25 & 8,1 \\
\hline & Unanswered & 1 & 0,3 \\
\hline & Total & 308 & 100,0 \\
\hline & $0-550 \mathrm{TL}$ & 76 & 24,7 \\
\hline & 560- $1000 \mathrm{TL}$ & 96 & 31,2 \\
\hline & $1001-2000$ & 71 & 23,1 \\
\hline
\end{tabular}




\begin{tabular}{llcc}
\hline Economic Income & 55 & 17,9 \\
& 5000 TL and $+5000 \mathrm{TL}$ & 8 & 2,6 \\
& Unanswered & 2 &, 5 \\
Total & 308 & 100
\end{tabular}

Based on Table 2, those in the age range of 21-23 years, those who have two siblings in terms of the number of siblings, those who spend most of their lives in the city, and those who have an economic income of 560-1000 TL represent the densest cluster in the relevant demographic categories.

The results of regression analysis for research hypotheses that constitute the main problem of the research, which focus on the impact of self-consistency (SC) [H1] and body image perception (BIP) [H6] on communication skills (CS), are in Table 3.

Table 3. Simple regression analysis for dependent and independent variables

\begin{tabular}{|c|c|c|c|c|c|c|c|}
\hline $\begin{array}{c}\text { Dependent } \\
\text { V. }\end{array}$ & $\begin{array}{l}\text { Independent } \\
\text { V. }\end{array}$ & $\mathbf{R}^{2}$ & $\begin{array}{c}\text { Std. } \\
\text { E. }\end{array}$ & $\mathbf{F}$ & $\beta$ & $\mathbf{t}$ & $\mathbf{p}$ \\
\hline \multirow[t]{2}{*}{$\mathrm{CS}$} & $\mathrm{SC}$ & .023 & 0.42 & 7.091 & .070 & 2.663 & .008 \\
\hline & BIP & .240 & 0.37 & 96.527 & .315 & 9.825 & .000 \\
\hline
\end{tabular}

Based on the R2 determination coefficients contained in Table 3, body image perceptions have a significant positive effect on the communication skills of students of the Faculty of Communication by $24.2 \%$. A one-unit increase in body image perceptions of SDU Faculty of Communication students leads to a 0.315 -unit increase in communication skills. Therefore, increasing students ' positive attitudes towards their own bodies also positively affects their communication skills. Self-consistency, on the other hand, has a very low effect of $2.3 \%$ on communication skills. One unit increase in the participants' selfconsistency levels causes an increase of 0.7 units on their communication skills. In addition to testing the $\mathrm{H} 1$ hypothesis, an ANOVA test was also used. As a matter of fact, in the proposition "H1: Self-consistency affects communication skills", the assumption that individuals with low self-consistency will tend to different discourses and behaviors to reach their ideal self is taken into consideration in line with the purpose of the research. The main reason for this is that people with low self-esteem are not satisfied with their current self, so 
they want to change their self. In this direction, since the people in question lean towards the changes, they cannot have a consistent self. Efforts to change the negative aspects of the individual and internalize the new features that they are trying to have required various communication skills. As mentioned in the previous paragraphs, internal dynamics and feedback from the external environment are important in forming a person's self-perception. For this reason, individuals with low self-consistency need to manage their impressions of the external environment and develop various communication skills. Positive changes in social comfort, interaction management, expression, listening skills, empathy, and many other communication skills can be expected among participants with low self-consistency levels who want to improve their existing self-perception. These skills can vary from person to person. Therefore, in addition to the regression analysis results, it would be appropriate to address the communication skills of individuals with low self-consistency levels. This analysis's main purpose is to make visible individuals' communication skills with low selfconsistency levels, medium, and high levels.

The self-consistency data set's averages were formed in three separate categories as low, medium, and high and became categorical variables. At the end of the Anova test carried out, the participants' communication skills differed significantly according to their self-consistency levels $(\mathrm{p}>.05)$. When the significant differences between binary groups are examined (Tukey), the communication skills of individuals with high self-consistency are higher than participants with intermediate communication skills $(.15169 *)$. On the other hand, when the averages for communication skills are analyzed, participants with low selfconsistency levels have a communication skill level of $\overline{\mathrm{x}}=3$.9. Participants with a medium self-consistency level have a communication skill level of $\bar{x}=3.8$. Participants with a high self-consistency level have a communication skill level of $\bar{x}=4.0$. Therefore, the fact that the participants' communication skills with low self-consistency are higher than those of medium self-consistency partially supports the H1 hypothesis. Individuals with lower selfconsistency levels are probably making more intensive efforts to improve their communication skills to change positively. In other words, it can be interpreted that individuals with low self-consistency levels are looking for ideal self-concepts by developing different discourses and behaviors to improve their communication skills. In this direction, the $\mathrm{H} 6$ and $\mathrm{H} 1$ hypothesis has been partially accepted based on the $\mathrm{R}^{2}$ coefficient in Table 3 and the related ANOVA test results. Further research is needed to clarify the relevant context and enrich the field. 
Table 4 shows the correlation analysis values in which the $\mathrm{H} 2$ hypothesis, which deals with the relationship between the participants' body image perceptions and self-consistency, is tested. Simultaneously, the relationship between the participants' body image perceptions and communication skills is in Table 4.

Table 4. Correlation Analysis Between Variables

\begin{tabular}{lccc}
\hline & $\mathbf{1}$ & $\mathbf{2}$ & $\mathbf{3}$ \\
\hline 1-Body Image Perception & 1 & $.217^{* *}$ & $.490^{* *}$ \\
2-Self-Consistency & 1 & $.150^{* *}$ \\
3-Communication Skills & & 1 \\
\hline$* * \mathrm{p}<.01, * \mathrm{p}<.05$ & & &
\end{tabular}

As a result of the Pearson correlation analysis, a significant positive relationship was found between students' body image perceptions and self-consistency $(r=.217, \mathrm{p}<.01)$. It can be interpreted that with the increase of students' positive attitudes towards their bodies, their self-consistency will increase positively. In this context, the H2 hypothesis was accepted. On the other hand, as shown in Table 4, there is a positive relationship between participants ' body image perceptions and communication skills $(\mathrm{r}=.490, \mathrm{p}<.01)$. In the literature, in cases where $r$ is greater than 0.8 , the relationship can be considered quite strong, and when $\mathrm{r}$ is less than 0.5 , the relationship can be considered weak. On the other hand, these values have a relative structure in interpreting the strength of the relationship. The interpretation may change according to the content of the subject and the type of data (Samuel and Ethelbert, 2015). Therefore, considering the regression results in Table 3, watching the participants' body image perceptions in a positive circle can positively improve their communication skills. New research on this subject is essential for clearer inferences.

Table 5. Body Image Perception According to Gender: T-Test

\begin{tabular}{|c|c|c|c|c|c|c|c|c|c|}
\hline & & & Gender & $\mathbf{N}$ & $\overline{\mathbf{x}}$ & SD & SE & $\mathbf{T}$ & $\mathbf{P}$ \\
\hline \multirow{2}{*}{$\begin{array}{l}\text { Body } \\
\text { (BIP) }\end{array}$} & \multirow[t]{2}{*}{ Image } & \multirow[t]{2}{*}{ Perception } & Female & 156 & 4.1639 & 65897 & ,05276 & \multirow{2}{*}{1,269} & \multirow{2}{*}{,205 } \\
\hline & & & Male & 152 & 4.0680 & 66680 & 05408 & & \\
\hline
\end{tabular}


The $\mathrm{H} 3$ hypothesis, which made the proposition that the participants' body image perceptions will differ according to gender, was rejected due to the t-test ( $p>.05$ ). The H4 hypothesis that the average Body Image Perception of female participants would be lower than that of men was also rejected based on the result "Female: $\bar{x}=4.1$; male: $\bar{x}=4.0$ " in Table 5 .

As a result of the ANOVA test for the H5 hypothesis, which deals with the differentiation of body image perception by age, it was concluded that the participants' body image perceptions did not differ significantly ( $p>$.05) to age. Accordingly, the H5 hypothesis was also rejected. As a matter of fact, the ages of most of the participants are close to each other since they are university students. In the literature, a change in body image is expected due to aging (Becker, Diedrichs, Jankowski \& Werchan, 2013). Relevant ANOVA test results are in Table 6.

Table 6. Differentiation Status of Body Image Perception According to Age

\begin{tabular}{lccccc}
\hline Source of Variance & $\begin{array}{c}\text { Sum of } \\
\text { Squares }\end{array}$ & df & Mean Square & F & Sig. \\
\hline Between G. & 3,320 & 4 &, 830 & 1,908 &, 109 \\
\hline Within G. & 131,833 & 303 &, 435 & \\
\hline Total & 135,153 & 307 & & & \\
\hline
\end{tabular}

The t-test results for the H6 hypothesis, which suggests that communication skills will differ for male and female participants, are in Table 7.

Table 7. Communication Skills According to Gender: T-Test

\begin{tabular}{lccccccc}
\hline & Gender & $\mathbf{N}$ & $\overline{\mathbf{x}}$ & SD & SE & T & P \\
\hline Communication Skills (CS) & Female & 156 & 3,9244 &, 41309 &, 03307 & & \\
& Male & 152 & 3,8137 &, 43569 &, 03534 & & \\
& & & & & & & \\
\hline
\end{tabular}


According to Table 7, female participants have a slightly higher average communication compared to men. Therefore, it can be stated statistically $(p<.01)$ that female students are more competent than male students in communication. New research is needed to clarify the relevant context and to make more consistent inferences. Based on the data in Table 7, the $\mathrm{H} 7$ hypothesis was accepted for this study based on the statistical results. The difference is of low value.

In summary, the H1-H2-H6-H7 hypotheses were accepted, while the H3-H4-H5 hypotheses were rejected.

\section{Discussion and Conclusion}

In this study, which questioned the effect of' body image 'and' self-consistency ' on communication skills, a study was conducted on Communication Faculty students who would perform communication acts as a profession. According to the results, perceived body image significantly affects communication skills. As mentioned in the conceptual background, the phenomenon of communication in the literature is more associated with the perception of body image in feedback received from the environment (Kichler \& Crowther, 2009; Pole, Crowther \& Schell, 2004; Arroyo and Andersen, 2016).

On the other hand, a limited number of previous studies (Ceyhan, Ceyhan \& Kuryılmaz, 2012; Woodrow-Keys, 2006; Rumsey \& Harcourt, 2004; Foustanos, Pantazi, \& Zavrides, 2007) addressing the effect of body image on communication skills shows that body image perception has a significant effect on the communication skills. Therefore, the results of the H6 hypothesis support the current literature. However, past research examines communication skills through lower components (e.g., self-confidence, assertiveness, social interaction, etc.). Within this research scope, the data collection tool about communication skills is not limited to a specific communication skill. Eleven key elements covering communication skills are included ${ }^{5}$. Therefore, the communication skills that are the subject of the study are more comprehensive. According to the results reached at the end of the research, body image perception positively affects a person's communication skills. Therefore, it can be commented that body image perception affects communication skills and affects communication processes in a general sense.

According to the research outputs, self-consistency has a very low statistically significant effect on communication skills (H1). Therefore, it can be stated that there is a

\footnotetext{
${ }^{5}$ For detailed information about communication skills, see the section " data collection tools".
} 
relationship between concepts. However, in order to define the effect between variables, new studies are needed on different sample sets. It is worth noting that personality traits continue to form in the university students' psychological framework in which the sample was selected. Indeed, $76 \%$ of the participants are between 18 and 23 years old. When the studies conducted on the concept of self in the literature are examined, a significant relationship has been found between individuals' self-consistency in higher age groups and their social expression styles that center the communication element (e.g., participation in local government) (Güler and Sezgin, 2020). On the other hand, the H1 hypothesis, based on the fact that participants with low self-consistency will develop different discourse and behavior styles to reach their ideal self, is accepted statistically. This situation is considered to be important for the literature. In particular, it is noteworthy for future research that individuals' communication skills in the high and low self-consistency category are higher than those of moderate self-consistency participants. Individuals with a low level of selfconsistency may place more emphasis on communication skills to change for the better.

A significant positive relationship $(\mathrm{r}=.217, \mathrm{p}<.01)$ was found between the participants' body image perceptions and self-consistency $(\mathrm{H} 2)$ supports the general opinion in the literature (Befort and Christie, 2001; Lowery et al., 2005). In the literature, it is stated that individuals who are satisfied with their self-have high self-esteem do not aim to change themselves, and their self-consistency is high (Elliott, 1986). The role of body image perception is quite effective in this regard. (Hwang, 2017). Therefore, it can be stated that people who are not satisfied with their body image will be open to change, and therefore their self-consistency is also low. (Elliott, 1986).

The analysis results, which tested the $\mathrm{H} 3$ and $\mathrm{H} 4$ hypotheses, show that women's body image perceptions were not lower than those of male participants. The output in question does not coincide with past literature. Previous studies have shown that women's perceptions of body image are lower than men's (Demarest \& Allen, 2000; Ata, Ludden \& Lally, 2007; Morken, Røysamb, Nilsen \& Karevold, 2019). In this regard, the formation of training that students of the Faculty of communication receive are effective. In communication faculties, it is frequently emphasized that appearance, body image, and other psychological factors are important for effective communication in basic textbooks (Ișik, 2017) and in practical activities since the first grades. Therefore, the participants had a more conscious structure in this regard than the other sample sets. Thus, students are indirectly aware that these factors affect the communication they have established through the 
education they receive. A student with a negative perception of body image may be making more effort to improve their body image perception than other people, both in order to be able to perform their profession and to live a happier life. Based on this result, it is thought that by providing relevant training to similar sample clusters, negative body image perceptions of women towards themselves can be prevented (indirectly). Because not only professionally, but also the quality of the communication that the individual has established with his / her social environment is under the influence of these factors at some point. Due to education on communication, individuals can have a more conscious thinking system.

Analysis of the $\mathrm{H} 7$ hypothesis shows that women are more competent in communication skills than men. The relevant result supports the outputs in the literature (Korkut, 1996; Ocak and Erşen, 2015; Akçam, Kanbay, Iş1k, 2019). Therefore, the gender factor is a distinguishing factor on communication skills, even on sample clusters where communication-oriented formation training is given.

In light of the data obtained from the research, the following points are recommended to the practitioners and researchers:

Body image perception appears to be an effective prerequisite for developing communication skills. Therefore, individuals should keep their body image perceptions in a positive circle at some point to increase the quality of their communication and to be more competent in the process in question. Although body image perception is a factor under the influence of many external factors, the individual can take various steps to change this perception in line with his preferences positively. Therefore, within the bounds of possibility, the person should question the source of the specific problem to improve his / her perception. He/she can also take care of his/her appearance and eat healthy and exercise. As a matter of fact, these activities are accepted by the general public and contribute positively to people's physiological and psychological structure. In this way, it is estimated that people will be less anxious about effective communication. On the other hand, new research is needed to make a clear conclusion.

Feedback from the environment affects the attitude of the person towards their body. Based on the data obtained from this study, it should be known that the process is not just this, and it should be taken into account that body image perception is an important component for effective communication. Therefore, individuals ' efforts to improve body image are also considered important in improving communication skills. For effective 
communication, it will be advantageous for individuals to become aware of this large-scale map of the process and to develop conscious behavior and discourses.

Researchers need to conduct research that addresses more broadly the relationship between self-consistency levels and communication skills. According to the results reached within the scope of this study, the communication skills of individuals with low and high self-consistency are quite similar. However, it was determined that the participants with medium self-consistency levels have lower communication skills than these two groups. From this situation, it is understood that individuals with low self-consistency level are not satisfied with themselves and will develop different discourse strategies to positively change themselves. In the following studies, the relevant context can be enriched by considering self-consistency in demographic factors (especially age) and personal development periods.

The first constraint is that the target population is limited only to students of the Faculty of communication of Suleyman Demirel University, taking into account time, transport, cost, and pandemic constraints. In this direction, the results reached at the end of the research can be generalized to students of the Faculty of Communication of Suleyman Demirel University and similar groups. On the other hand, due to the Covid-19 pandemic, data was collected by online interview programs, telephone, e-mail, and social media tools during the 2019-2020 Academic Spring Semester. Therefore, due to the time interval in which the study was carried out, it offers a certain time section. In cross-sectional research designs, data is collected at one time over a certain period of time. In this aspect, crosssectional research designs are like instant photography (Durna, 2014). In this respect, the cross-sectional design of the research and the collection of data in electronic media due to the pandemic are also among the study's limitations.

Ethical Approval: Ethical approval regarding the research was obtained from Süleyman Demirel University Ethics Committee on 25.06.2020 with the decision number 92/3, and the current procedure was carried out within the framework of ethical decisions.

Conflict Interest: The authors declare that they have no conflict of interest.

Authors Contributions: Authors contributed equally and are listed in alphabetical order. 


\section{References}

Akçam, A., Kanbay, Y. \& Iş1k, E. (2019). Hemşirelik Öğrencilerinin İletişim Becerilerinin Değerlendirilmesi. Artvin Çoruh Üniversitesi Uluslararası Sosyal Bilimler Dergisi, 5(2), 74-92.

Allred, R. J., \& Atkin, D. (2020). Cell Phone Addiction, Anxiety, and Willingness to Communicate in Face-to-Face Encounters. Communication Reports, 33(3), 95-106.

Anlı, G., Akın, A., Eker, H. \& Özçelik, B. (2015). Bedeni beğenme ölçeği: geçerlik ve güvenirlik çalışması. The Journal of Academic Social Science Studies, 36(2), 505511.

Arroyo, A. \& Andersen, K. K. (2016). Appearance-related communication and body image outcomes: Fat talk and old talk among mothers and daughters. Journal of Family Communication, 16(2), 95-110.

Ata, R. N., Ludden, A. B. \&Lally, M. M. (2007). The effects of gender and family, friend, and media influences on eating behaviors and body image during adolescence. Journal of Youth and Adolescence, 36(8), 1024-1037.

Banfield, S. S. \& McCabe, M. (2002). An evaluation of the construct of body image. Adolescence, 37(146), 373-393.

Batuş, G., Alver, F., Arık, B., Çoban, B. \& Çı̆̆g, Ü. (2006). Kadife Karanlık. İstanbul: Su Yayınlar1.

Becker, C. B., Diedrichs, P. C., Jankowski, G. \& Werchan, C. (2013). I'm not just fat, I'm old: has the study of body image overlooked "old talk"? Journal of Eating Disorders, $1(1), 1-12$.

Befort, C., Hull-Blanks, E. E., Huser, L. \& Sollenberger, S. (2001). Body image, selfesteem, and weight-related criticism from romantic partners. Journal of College Student Development, 42(5), 407-419.

Bienvenu Sr, M. J. (1971). An interpersonal communication inventory. Journal of Communication, 21(4), 381-388.

Böke, K. (2014). Örnekleme. K. Böke (Ed.), Sosyal Bilimlerde Araştırma Yöntemleri içinde (104-149), İstanbul: Alfa Basım Yayım Dağıtım. 
Cash, T. E. \& Henry, P. E. (1995). Women's body images: The results of a national survey in the U.S.A. Sex Roles, 33(1/2), 19-28.

Ceyhan, A., Ceyhan, E., \& Kurtyilmaz, Y. (2012). The effect of body image satisfaction on problematic internet use through social support, problem-solving skills, and depression. The Online Journal of Counselling and Education, 1(3), 83-95.

Clark, L. \& Tiggemann, M. (2007). Sociocultural influences and body image in 9 to 12year-old girls: The role of appearance schemas. Journal of Clinical Child and Adolescent Psychology, 36(1), 76-86.

Çuhadaroğlu, F. (1986). Adolesanlarda benlik saygısı. Doktora tezi, Hacettepe Üniversitesi, Sosyal Bilimler Enstitüsü, Ankara.

Cusumano, D. L. \& Thompson, J. K. (2001). Media influence and body image in 811-year-old boys and girls: A preliminary report on the multidimensional media influence scale. International Journal of Eating Disorders, 29(1), 37-44.

Demarest, J. \& Allen, R. (2000). Body image: Gender, ethnic, and age differences. The Journal of Social Psychology, 140(4), 465-472.

Donnellan, M. B., Trzesniewski, K. H., Robins, R. W., Moffitt, T. E. ve Caspi, A. (2005). Low self-esteem is related to aggression, antisocial behavior, and delinquency. Psychological Science, 16(4), 328-335.

Duğan, Ö., Balcı, E. V. \& Tiryaki, S. (2017). Yabancı uyruklu ve Türk öğrencilerin iletişim becerilerinin karş1laştırılması: Uşak Üniversitesi örneği. Sobider, 4 (13), 227-242.

Durna, T. (2014). Nedensellik ve araştırma tasarımları. K. Böke (Ed.), Sosyal Bilimlerde Araştırma Yöntemleri İçinde (153-197). İstanbul: Alfa Basım Yayım Dağıtım.

Elliott, G. (1986). Self-Esteem and self-consistency: A Theoretical and Empirical link between two primary motivations. Social Psychology, 49 (3), 207-218.

Engel, M. (1959). The stability of the self-concept in adolescence. The Journal of Abnormal and Social Psychology, 58(2), 211-215.

Erikson, E. H. (1956). The problem of ego identity. Journal of the American Psychoanalytic Association, 4(1), 56-121.

Ersanlı, K. \& Balcı, S. (1998). İletişim becerileri envanterinin geliştirilmesi: Geçerlik ve güvenirlik çalışması. Türk Psikolojik Danışma ve Rehberlik Dergisi, 2(10), 7-12. 
Foustanos, A., Pantazi, L., \& Zavrides, H. (2007). Representations in plastic surgery: the impact of self-image and self-confidence in the work environment. Aesthetic Plastic Surgery, 31(5), 435-442.

Gardner, R. M. (1996). Methodological issues in the assessment of the perceptual component of body image disturbance. British Journal of Psychology, 87(2), 327337.

Giananti, A. (2020). I know how I know: perception, self-awareness, self-knowledge. Synthese. Advanced online publication. https://doi.org/10.1007/s11229-020-02726-9

Goffman, E. (2014). Günlük yaşamda benliğin sunumu. Çev: Barış Cezar, (3. Baskı). İstanbul: Metis Yayınları.

Grogan, S. (2006). Body image and health: Contemporary perspectives. Journal of Health Psychology, 11(4), 523-530.

Güler, Ş. \& Sezgin, M. (2020). Benlik saygısı ve e-katılım ilişkisi: Twitter ekseninde akademisyenlere yönelik bir uygulama. Pamukkale Üniversitesi Eğitim Fakültesi Dergisi, 49, 413-438.

Hair, J. F., Black, W. C., Babin, B. J., Anderson, R. E. \& Tatham, R. L. (2014). Multivariate Data Analysis. (Seventh Edition). Pearson Education Limited.

Hattie, J. (2014). Self-concept. New York - London: Psychology Press.

Hwang, R. H. (2017). Self-esteem, body image, and factors influencing the depression of infertile women. Journal of Digital Convergence, 15(10), 537-549.

Işık, M. (2017). Sizinle İletişebilir miyiz? Konya: Eğitim Yayınevi.

Jacobson, E. (2004). Kendilik ve nesne dünyast. S. Yazgan (Çev.),. İstanbul: Metis Yayınları.

James, W. (1983). The principles of psychology. Cambridge: Harvard University Press.

Kichler, J. C. \& Crowther, J. H. (2009). Young girls' eating attitudes and body image dissatisfaction: Associations with communication and modeling. The Journal of Early Adolescence, 29(2), 212-232.

Korkmaz, M. (1996). Yetişkin örneklem için bir benlik saygısı ölçeğinin güvenirlik ve geçerlik çalışması. Yüksek Lisans Tezi, Ege Üniversitesi Sosyal Bilimler Enstitüsü, İzmir. 
Korkut, F. (2016). İletişim becerilerini değerlendirme ölçeğinin geliştirilmesi: güvenirlik ve geçerlik çalışmaları. Türk Psikolojik Danışma ve Rehberlik Dergisi, 2(7), 18-23.

Liberman, Z., Woodward, A. L., Keysar, B. \& Kinzler, K. D. (2017). Exposure to multiple languages enhances communication skills in infancy. Developmental Science, 20(1), $1-11$.

Lowery, S. E., Kurpius, S. E. R., Befort, C., Blanks, E. H., Sollenberger, S., Nicpon, M. F. \& Huser, L. (2005). Body image, self-esteem, and health-related behaviors among male and female first-year college students. Journal of College Student Development, 46(6), 612-623.

Marsh, H. W. \& Shavelson, R. (1985). Self-concept: Its multifaceted, hierarchical structure. Educational Psychologist, 20(3), 107-123.

Morken, I. S., Røysamb, E., Nilsen, W. \& Karevold, E. B. (2019). Body dissatisfaction and depressive symptoms on the threshold to adolescence: Examining gender differences in depressive symptoms and the impact of social support. The Journal of Early Adolescence, 39(6), 814-838.

Neiss, M. B., Sedikides, C., \& Stevenson, J. (2002). Self-esteem: a behavioral genetic perspective. European Journal of Personality, 16(5), 351-367.

Ocak, G. \& Erşen, B. Z. (2019). Öğretmen adaylarının iletişim becerileri algılarının incelenmesi. Mehmet Akif Ersoy Üniversitesi Eğitim Fakültesi Dergisi, 33, 1 - 19.

Pole, M., Crowther, J. H. \& Schell, J. (2004). Body dissatisfaction in married women: The role of spousal influence and marital communication patterns. Body Image, 1(3), 267-278.

Razı, G. S., Kuzu, A., Yıldız, A. N., Ocakcı, A. F., \& Arifoğlu, B. Ç. (2009). Çalışan gençlerde benlik saygısı, iletişim becerileri ve stresle baş etme. TAF Preventive Medicine Bulletin, 8(1), 17-26.

Righetti, F. \& Visserman, M. (2018). I gave too much: Low self-esteem and the regret of sacrifices. Social Psychological and Personality Science, 9(4), 453-460.

Rosenberg, M. (1965). Society and the adolescent self-image. NJ: Princeton University Press.

Rosenberg, M. (1979). Conceiving the Self. New York: Basic Books. 
Rosenberg, M. (1989). Self-concept research: A historical overview. Social Forces, 68(1), 34-44.

Rubin, R. B. \& Martin, M. M. (1994). Development of a measure of interpersonal communication competence. Communication Research Reports, 11(1), 33-44.

Rumsey, N., \& Harcourt, D. (2004). Body image and disfigurement: issues and interventions. Body Image, 1(1), 83-97.

Samuel, M. \& O., Ethelbert, L. (2015). The relevance and significance of correlation in social science research. International Journal of Sociology and Anthropology Research, 1(3), 22-28.

Schmitt, D. P. \& Allik, J. (2005). simultaneous administration of the Rosenberg self-esteem scale in 53 nations: exploring the universal and culture-specific features of global self-esteem. Journal of Personality and Social Psychology, 89(4), 623-642.

Schooler, D., Ward, L. M., Merriwether, A. \& Caruthers, A. (2004). Who's that girl: Television's role in the body image development of young white and black women. Psychology of Women Quarterly, 28(1), 38-47.

Sezgin, M., \& Güler, Ş. The role of digital feedback on the self-esteem of digital natives. Türkiye Illetişim Araştırmaları Dergisi, (35), 46-62.

Shavelson, R. J., Hubner, J. J. \& Stanton, G. C. (1976). Validation of construct interpretations. Review of Educational Research, 46, 407-441.

Slade, P. D. (1994). What is body image? Behaviour Research and Therapy, 32(5), 497-502.

Slater, A. \& Tiggemann, M. (2016). Little girls in a grown-up world: Exposure to sexualized media, internalization of sexualization messages, and body image in 6-9-year-old girls. Body Image, 18, 19-22.

Stewart, J., Zediker, K. \& Witteborn, S. (2005). Together: Communicating interpersonally: a social construction approach, 6th eds. Los Angeles, CA: Roxbury

Tylka, T. L. \& Wood-Barcalow, N. L. (2015). The Body Appreciation Scale-2: Item refinement and psychometric evaluation. Body Image, 12(January), 53-67. https://doi.org/10.1016/j.bodyim.2014.09.006.

Ünal, S. (2012). Evaluating the effect of self-awareness and communication techniques on nurses' assertiveness and self-esteem. Contemporary Nurse, 43(1), 90-98. 
M. Sezgin, \& Ş. Güler / Pamukkale University Journal of Education, 52, 206-234, 2021

Vani, M. F., Pila, E., Willson, E., \& Sabiston, C. M. (2020). Body-related embarrassment: The overlooked self-conscious emotion. Body Image, 32(March), 14-23. https://doi.org/10.1016/j.bodyim.2019.10.007.

Vatankhah, H., Daryabari, D., Ghadami, V., \& Naderifar, N. (2013). The effectiveness of communication skills training on self-concept, self-esteem, and assertiveness of female students in guidance school in Rasht. Procedia-Social and Behavioral Sciences, 84, 885-889.

Wiemann, J. (2003). Foreword. In J. Greene \& B. Burleson (Eds), In Handbook of communication and social interaction skills. Mahwah, NJ: Lawrence Erlbaum.

Woodrow-Keys, E. (2006). The effects of body image on career decision making, selfefficacy, and assertiveness in female athletes and non-athletes (Doctoral dissertation, Marshall University Libraries).

Zivnuska, S., Carlson, J. R., Carlson, D. S., Harris, R. B. \& Harris, K. J. (2019). Social media addiction and social media reactions: The implications for job performance. The Journal of Social Psychology, 159(6), 746-760. 